\title{
The Impact of Personal, Family and Social Factors on Psychological Well- being of Patients with Breast Cancer to Develop a Structural Model
}

\author{
Maryam Soleyman Farokh ${ }^{1}$, Ali Delavar ${ }^{2}$
}

1. PhD Student, Islamic Azad University, Tehran Branch, Tehran, Iran

2. Professor of Research Methods and Statistics, Allameh Tabataba'i University, Tehran, Iran

\begin{tabular}{ll}
\hline \multicolumn{1}{c}{ Article Info } & ABSTRACT \\
\cline { 3 - 3 } $\begin{array}{l}\text { Received: } 2020 / 01 / 21 ; \\
\text { Accepted: } 2020 / 03 / 30 ;\end{array}$ & $\begin{array}{l}\text { Introduction: Cancer is one of the most important diseases of the current century and the } \\
\text { third leading cause of death after cardiovascular disease and accidents, and affects the } \\
\text { psychological well-being of cancer patients. The aim of this study was to determine the effect } \\
\text { of individual, family and social factors on the psychological well-being of patients with breast } \\
\text { cancer in order to develop a structural model. }\end{array}$
\end{tabular}

10.30699/ajnmc.28.4.45

Original Article

Use your device to scan and read the article online

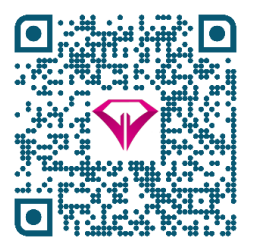

Methods: The present study was descriptive in the form of structural equation modeling. Its statistical population consisted of all women with breast cancer being treated in medical centers and specialized hospitals for cancer in Tehran in the first quarter of 2019 (1350 people). The statistical sample was determined based on the research plan of 300 people and using multi-stage clustering method, clustering of medical centers based on geographical areas and then selection of a cluster was performed randomly. Data were collected using Reef's psychological well-being questionnaires, Baer et al.'s mindfulness, five neo-personality factors, Connor and Davidson's resilience, Ritchie and Fitzpatrick's family communication patterns, and Zymet's social support. Finally, the data were analyzed using multivariate linear regression test in the text of structural equation modeling and by AMOS software version 21.

Results: The results of model analysis indicated that among the individual factors, the openness to experience, positively and neurosis has a negative effect on psychological wellbeing $(P<0.01)$. Also, resilience and mindfulness have both positively increased mental wellbeing $(P<0.01)$. In the case of familial factors and among the family communication patterns, the factor of orientation of conformity has reduced mental well-being $(P<0.01)$. Finally, social support can increase psychological well-being $(P<0.05)$.

Conclusion: Thus, it can be acknowledged that, despite the difficult physical conditions that people with cancer face, it is possible to take appropriate social support to strengthen the resilience of these patients and finally, expect that the ability to adapt and cope with cancer will also increase in people with the disease.

Keywords: Psychological well-being, Breast cancer, Personal factors, Family factors, Social factors

Copyright (C) 2020, This is an original open-access article distributed under the terms of the Creative Commons Attribution-noncommercial 4.0 International License which permits copy and redistribution of the material just in noncommercial usages with proper citation.

How to Cite This Article:

Soleyman Farokh M, Delavar A. The Impact of Personal, Family and Social Factors on Psychological Well-being of Patients with Breast Cancer to Develop a Structural Model. Avicenna J Nurs Midwifery Care. 2020; 28 (4)45-61 
تأثير عوامل فردى، خانوادگى و اجتماعى در بهزيستى روانشناختى بيماران مبتلا به سرطان يستان: تدوين يك مدل ساختارى

\section{مريم سليمان فرخ'، على دلاور}

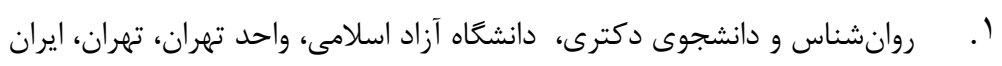

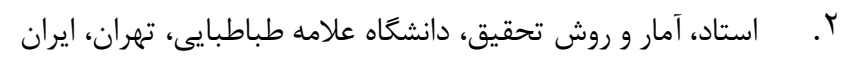

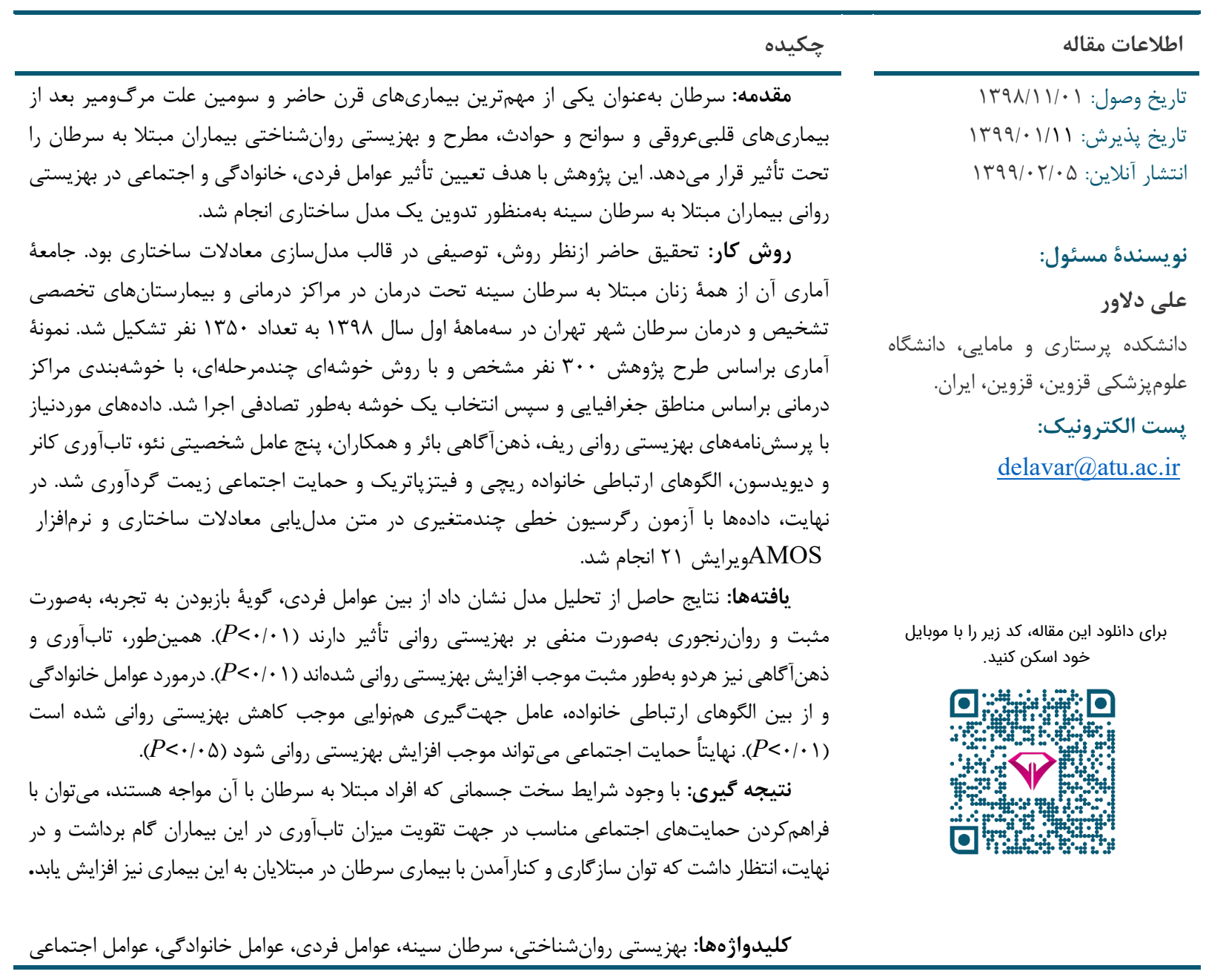

مقدمه

توسعهيافته است [F]. در اين ميان، سرطان سينه شايعترين،

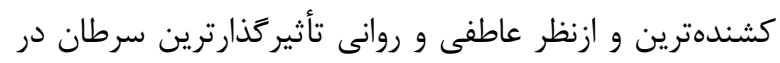

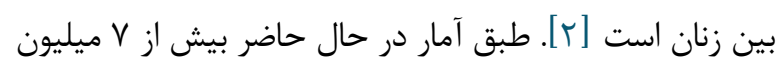

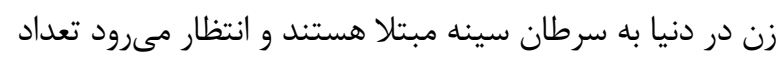

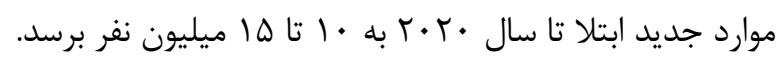
در ايران اين نوع سرطان دومين سرطان شايع در زنان بوده و

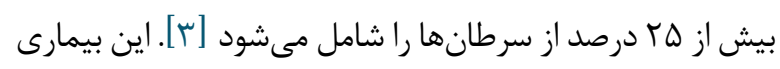

سرطان بهعنوان يكى از مهممترين بيمارىهاى قرن حاضر و سومين علت مرگومير بعد از بيمارىهاى قلب و عروق و سوانح

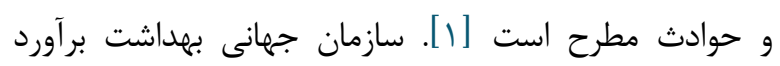

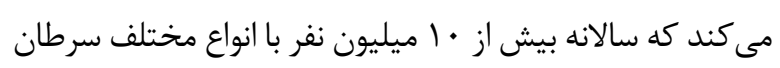
تشخيص داده مىشوند [ب]. انتظار مىرود تعداد موارد جديد

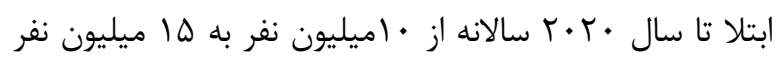

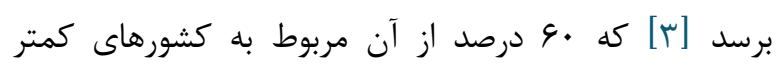


روانى ` بيماران مبتلا به سرطان سينه بسيار مهم است [ [ 1]. با

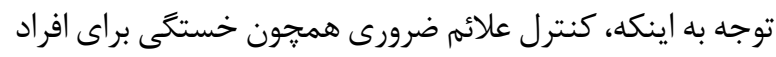

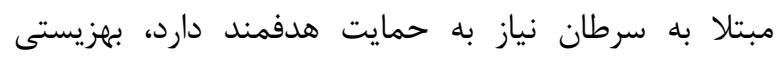

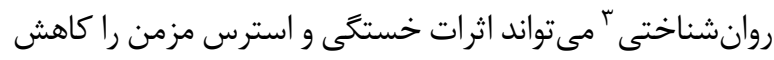

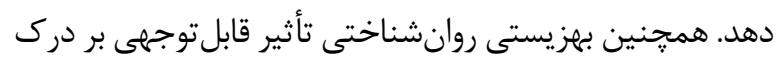

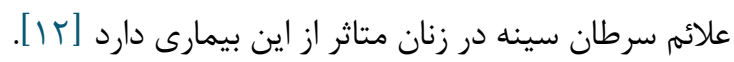

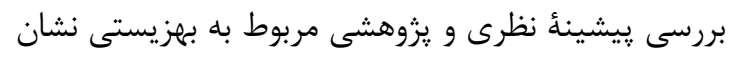

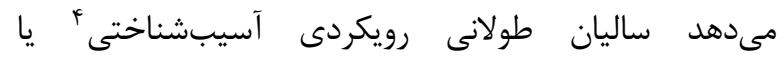

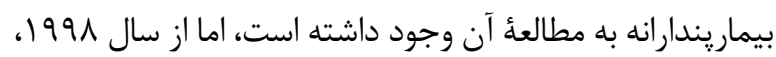

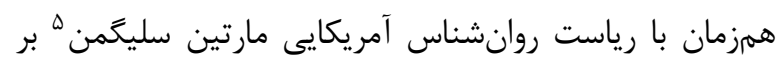

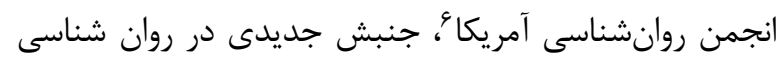

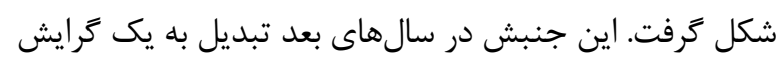

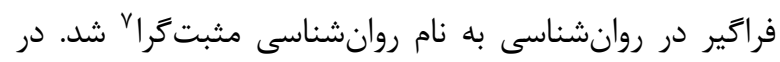

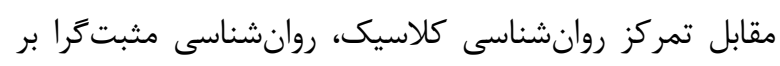

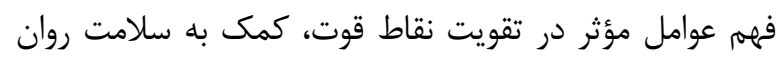

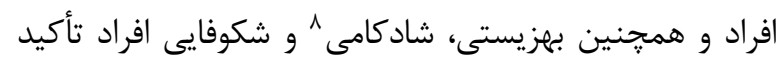

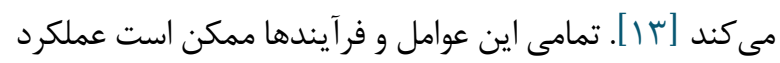

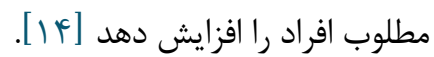

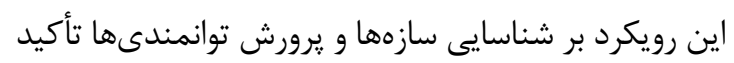

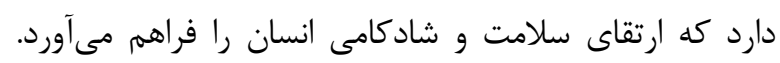

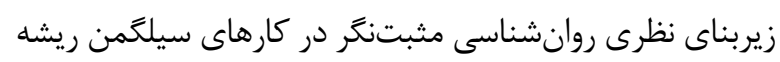

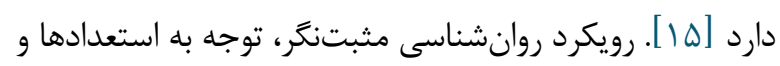

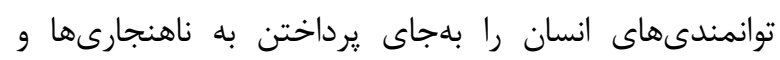

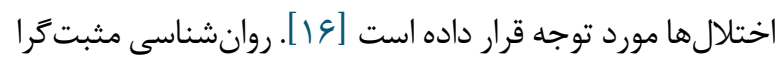

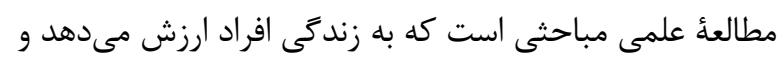

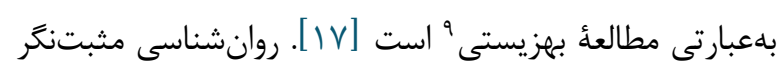

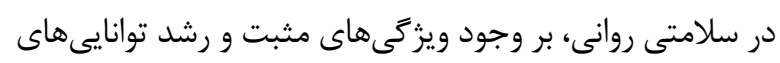

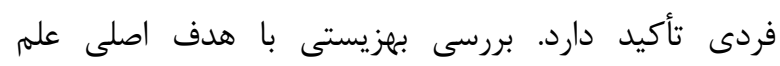

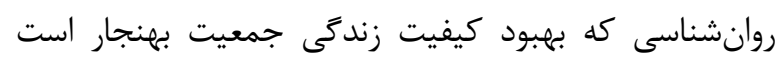

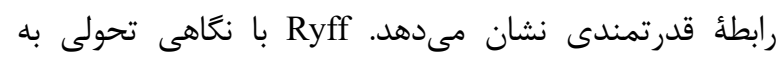

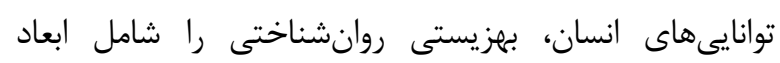

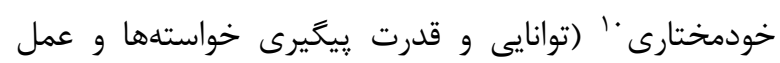

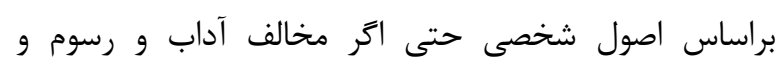

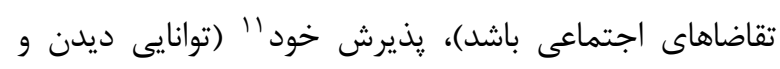

\footnotetext{
7. Positive psychology

${ }^{8}$. Happiness

9. Well-being

10. Autonomy

${ }^{11}$. Self-acceptance
}

مسير زندكى فرد را تغيير مىدهد و مشكلات فراوانى درتمام

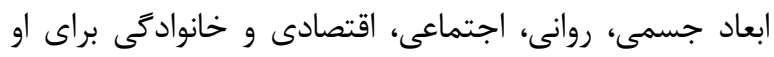

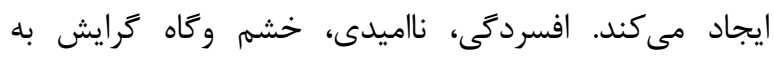

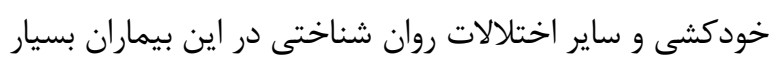

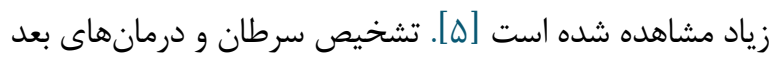

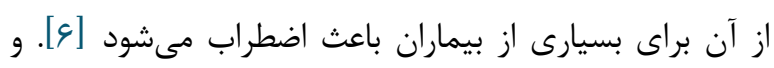

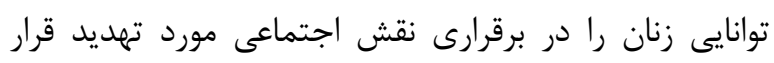

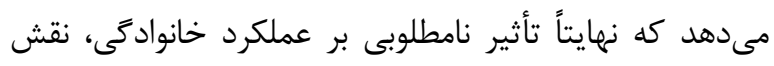

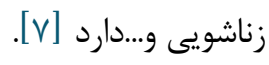
سرطان يكى از مهمترين بيمارىهاى قرن حاضر است و

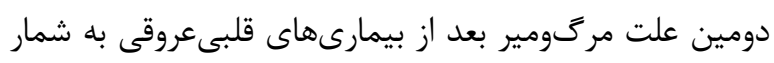

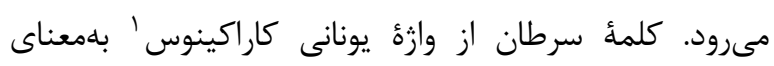

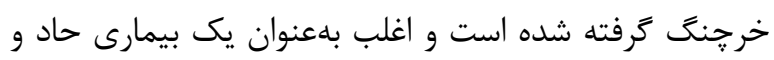

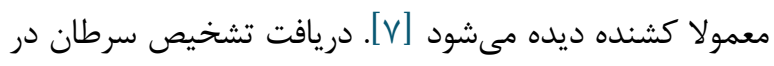

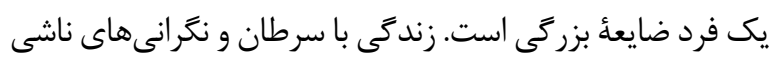

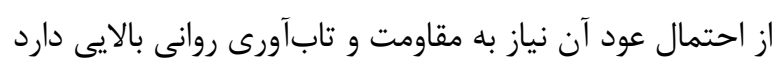

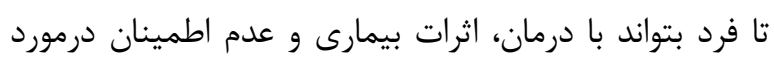

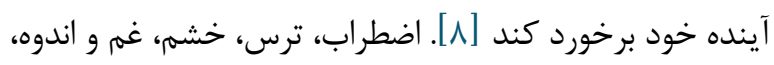
احساسات رايجى هستند كه ممكن است بيمار و اطرافيانش

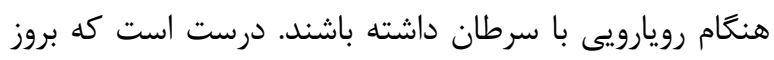

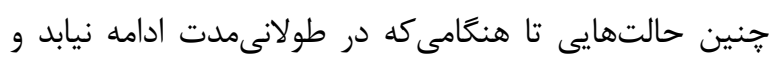

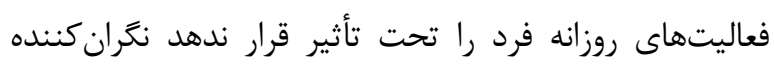

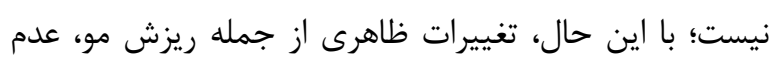

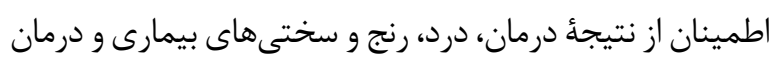

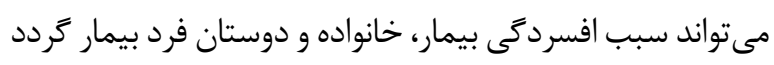

سرطان سينه، با توجه به افزايش ميزان بقا، عوارض و

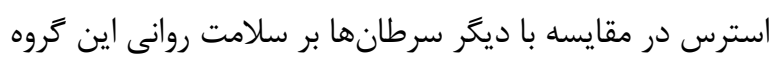

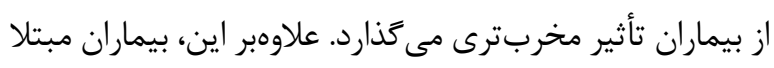

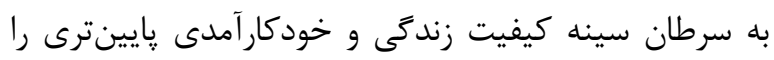

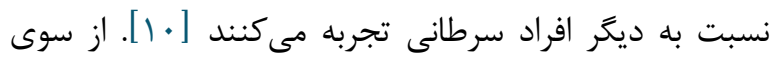

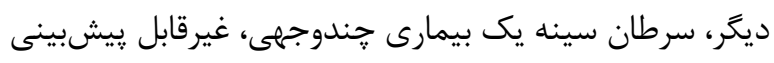

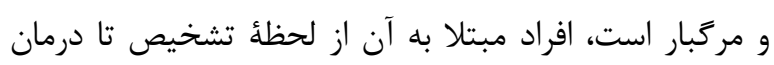

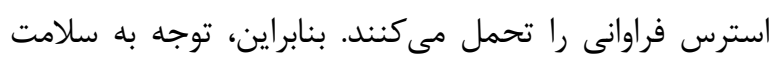

1. Karakinos

2. Mental health

3. Pshychological well-being

4. Pathologic

5. Seligman

${ }^{6}$. American psychological association 


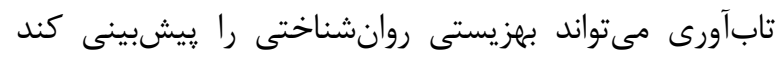

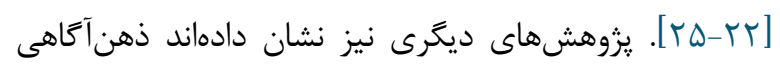

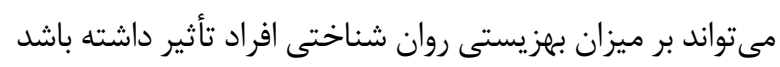

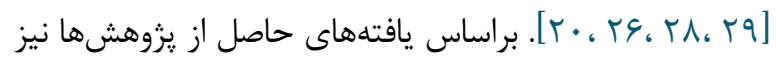

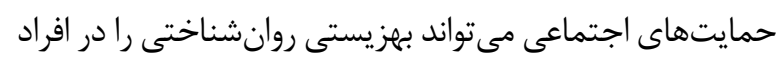

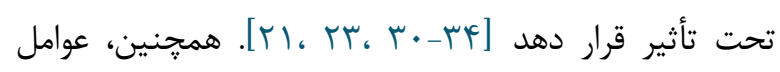

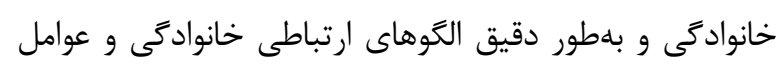

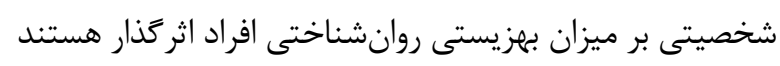

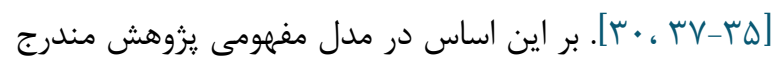

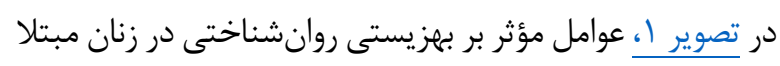
به سرطان سينه مشخص شده است.

\section{روش بررسى}

تحقيق حاضر ازنظر روش، توصيفى در قالب مدلسازى

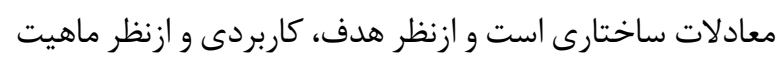

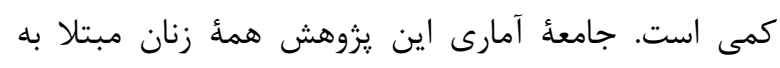

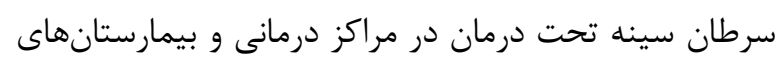

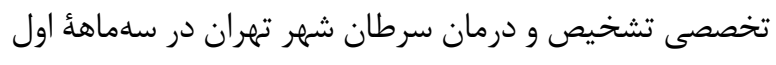

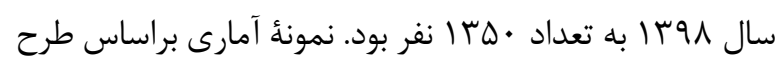

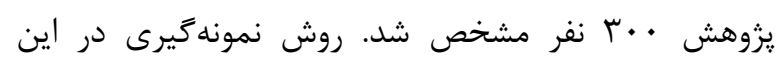

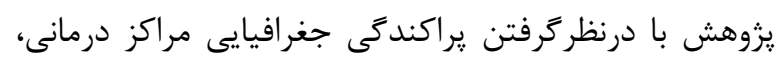

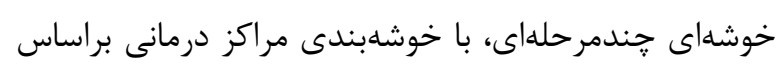

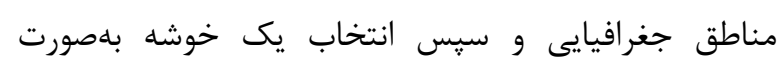

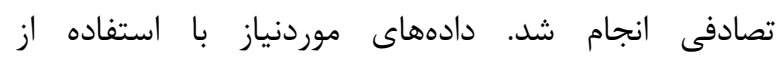

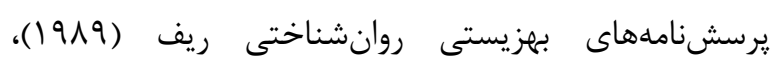

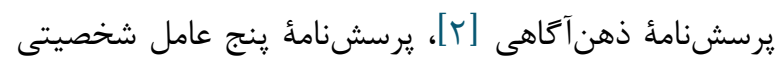

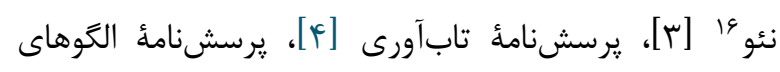

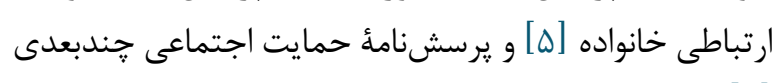

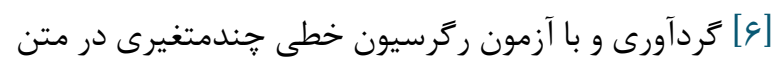

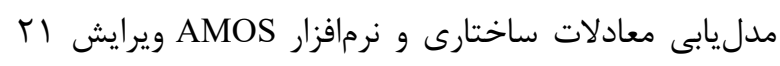
انجام شد. - ائ معاد

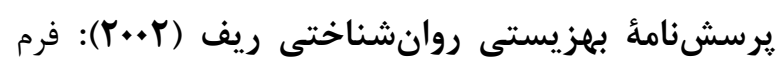

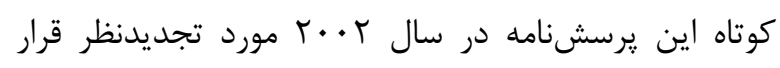

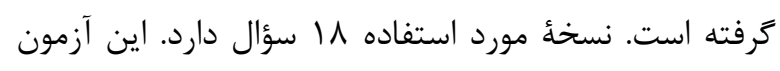
نوعى ابزار خودسنجى است كه در يك پيوستار ه درجهاى

\footnotetext{
15. Environmental mastery

${ }^{16}$. Neo big Five personality traits test
}

يذيرفتن نقاط ضعف و قوت خود)، رشد فردى ז" (احساس اينكه

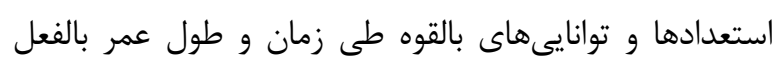

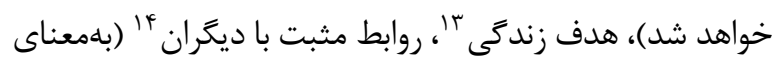

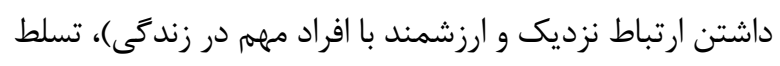

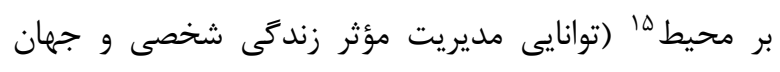

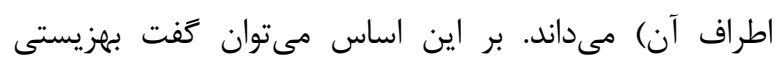

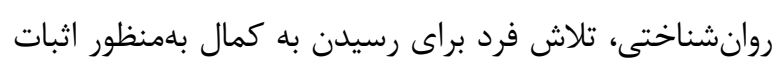

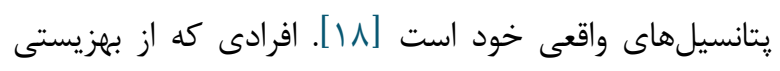

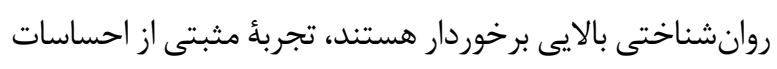

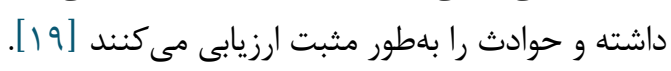

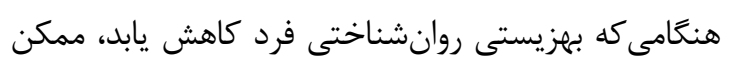

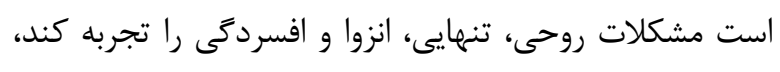

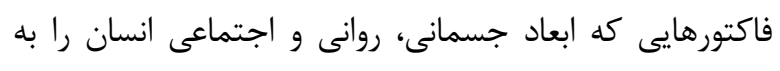

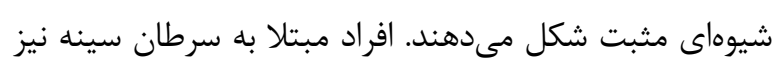
جنانكه از بهزيستى روان شناختى بالايى برخوردار باشند توانيى دهني

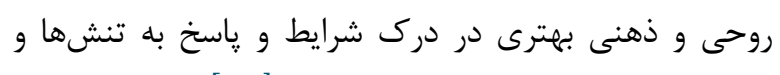

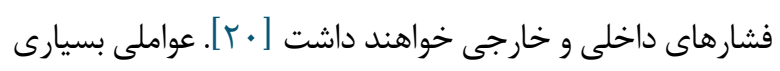

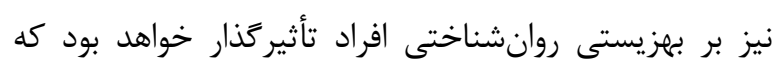

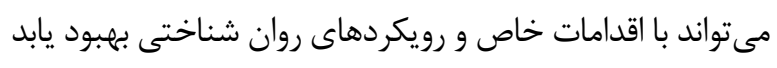

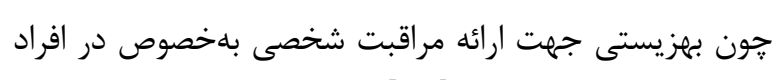

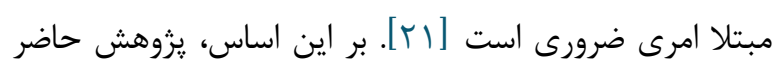

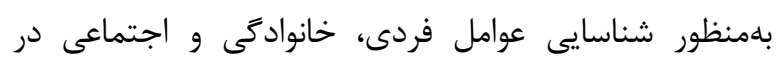

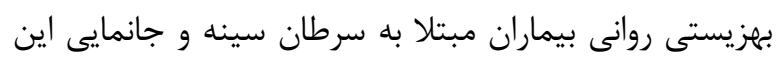

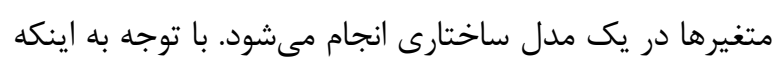

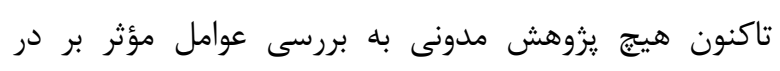

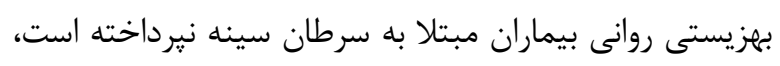

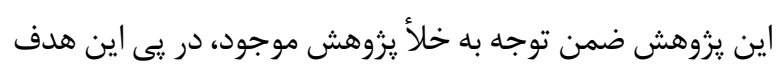

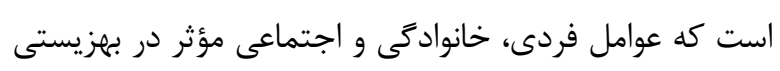

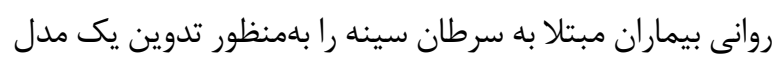
ساختارى شناسايى نمايد.

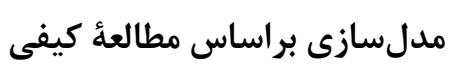

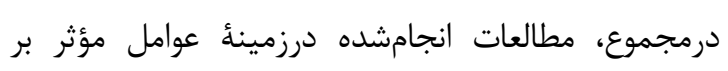

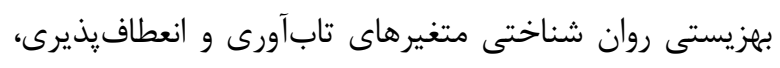

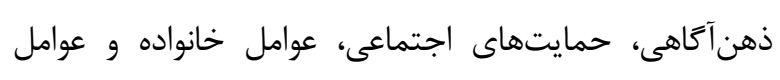

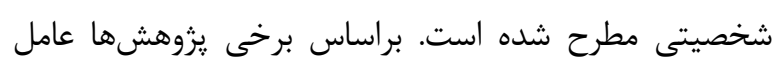

\footnotetext{
12. Personal growth

13. Purpose in life

${ }^{14}$. Positive relations with others
} 
مقياس اصلى از • •/ • تا A9/• در نوسان بوده است. در ايران

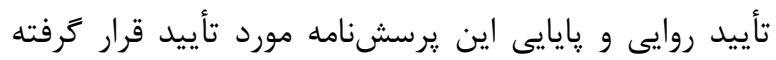

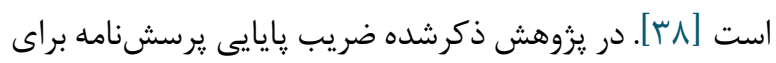

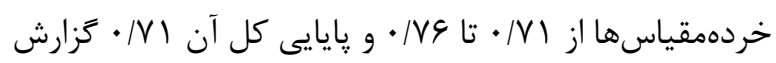
شده است.
ياسخ داده مىشود. بر اين اساس ززينه (خيلى مخالفم) نمره ا و كزينه (خيلى موافقم) نمره ه دريافت مى كند. نمرهٔ بالاتر نشاندهندة بهزيستى روانشناختى بهتر است. سؤالات شماره

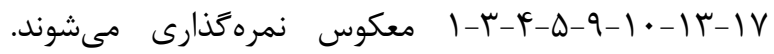

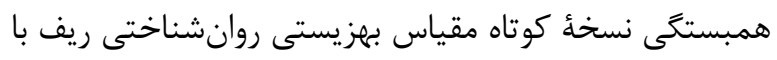

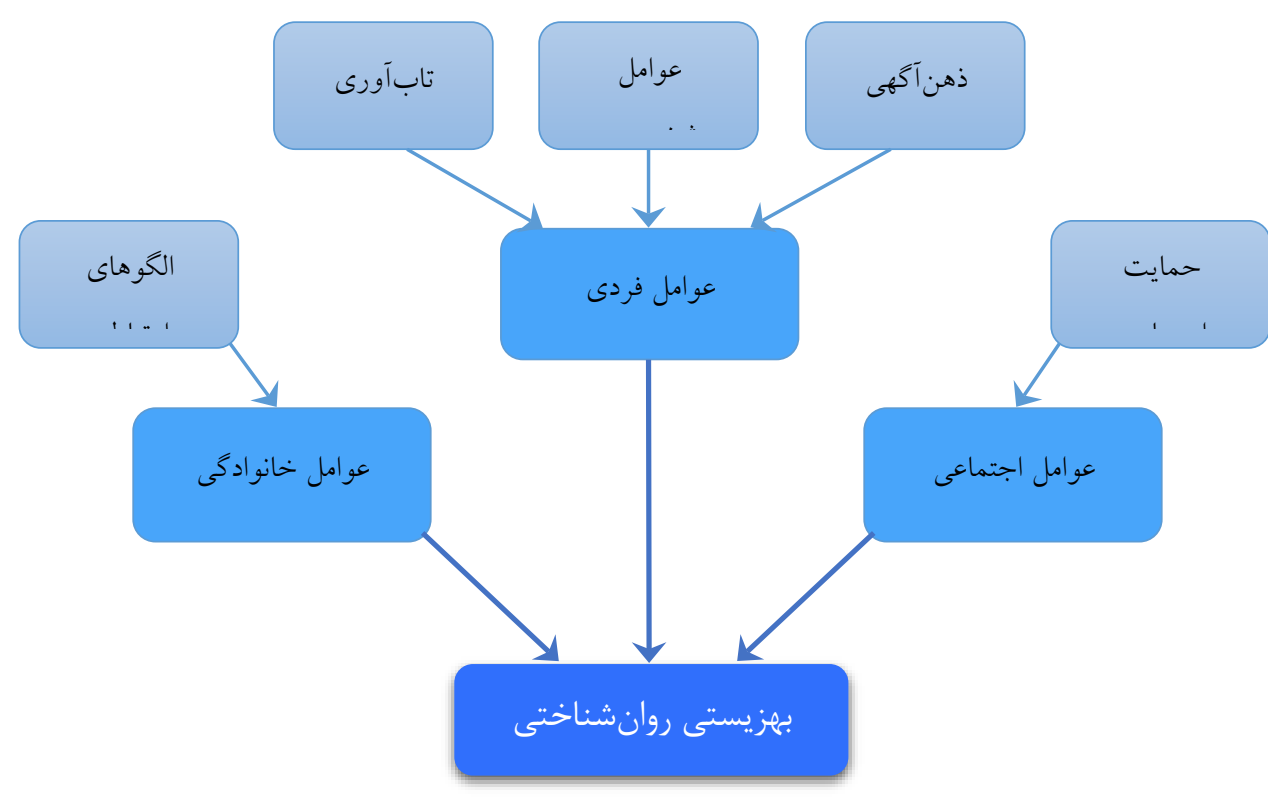

تصوير 1. مدل مفهومى يثوهش

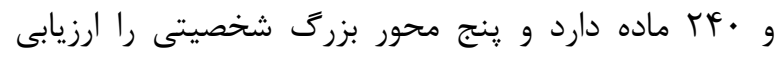

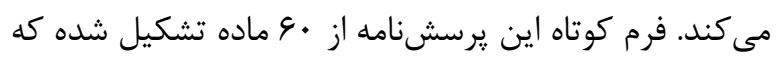

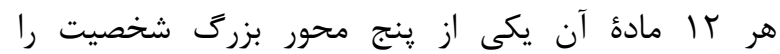

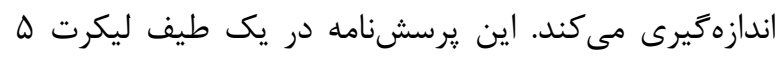

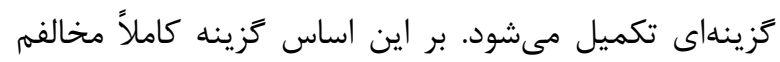
(نمره ()، مخالفم (نمره ؟)، نه موافقم نه مخالفم (نمره ؟َ)،

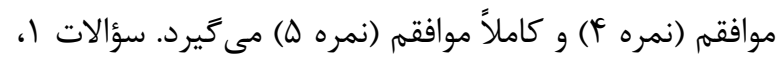

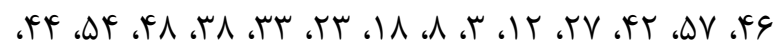

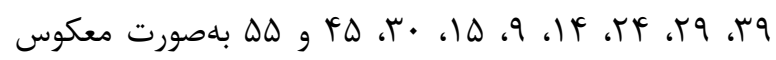

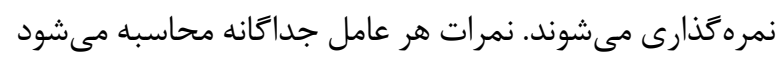

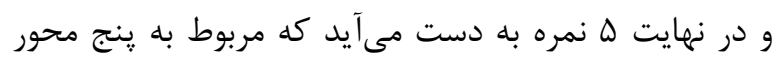

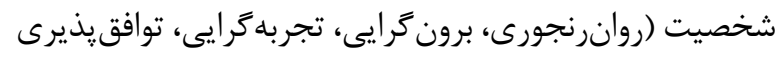

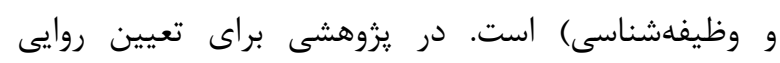

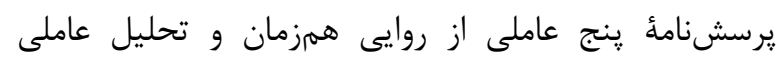

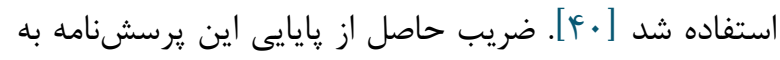

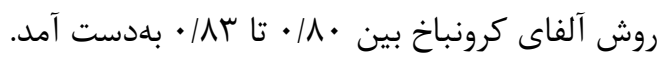

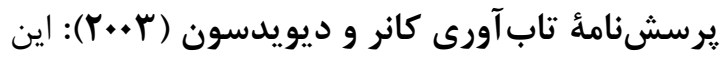

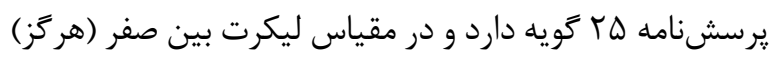
و ها (هميشه) نمرهخذارى مىشود. اين مقياس اكرجه سطوح

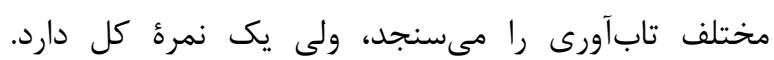

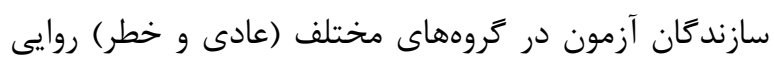

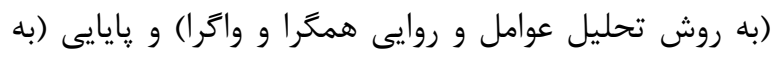

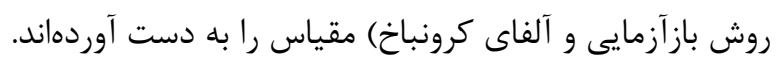

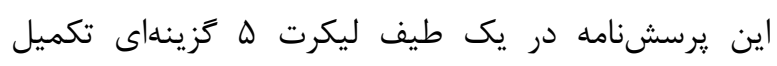

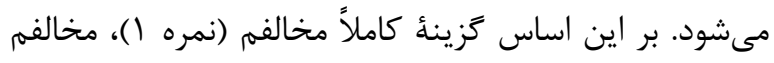

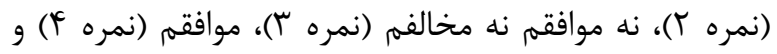

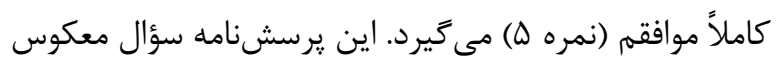

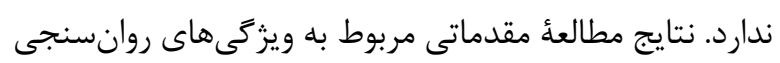

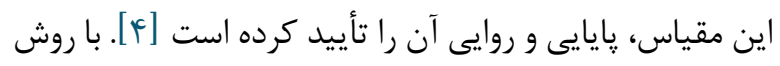

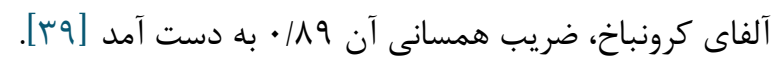

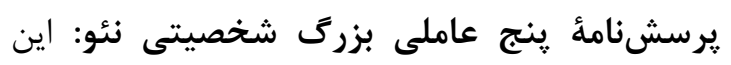

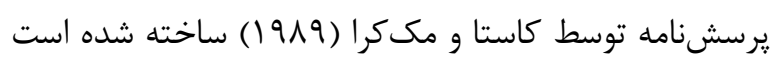


خودسنجى است و ميزان موافقت يا عدم موافقت ياسخدهنده را با عץ گَيه كه درباره وضعيت ارتباطات خانواده وى هستند. اين برسشنامه در يك طيف ليكرت ه تزينهاى تكميل

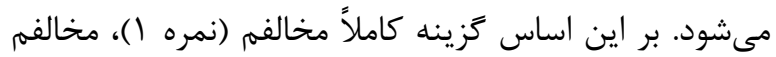

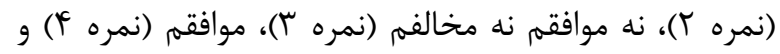

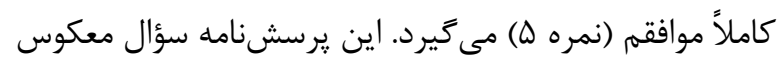

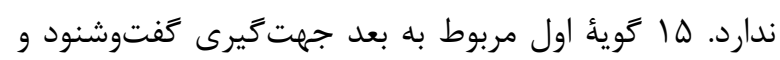

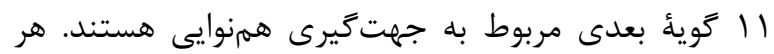

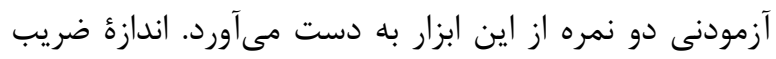

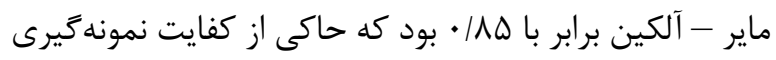

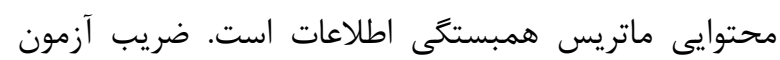

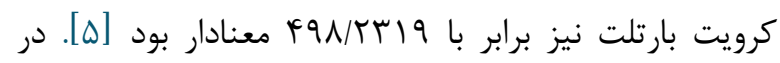

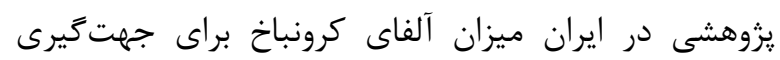

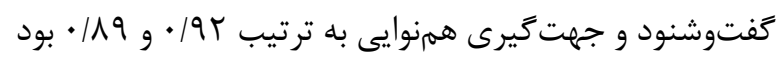

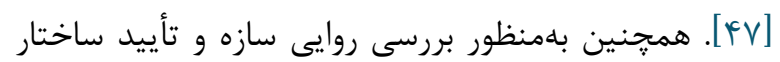

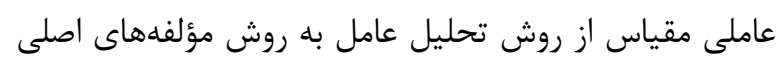

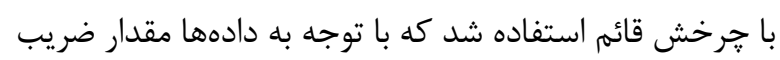
KMO

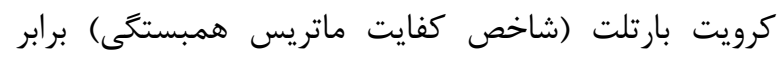
TFAF/AF

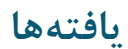

در جدول I آمار توصيفى مربوط به نمرات متغيرهاى تحقيق و هر يك از مؤلفههاى آن آمده است

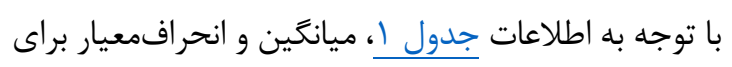

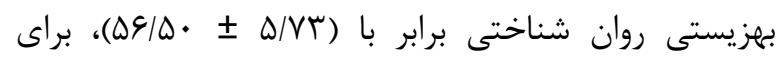

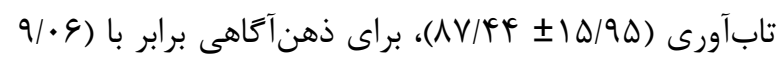
د

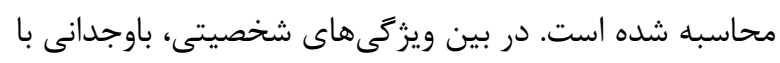

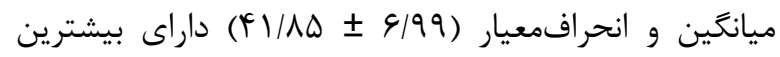

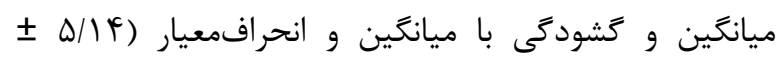

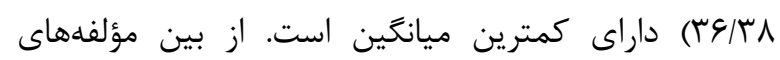

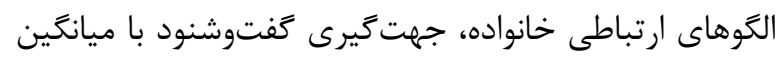

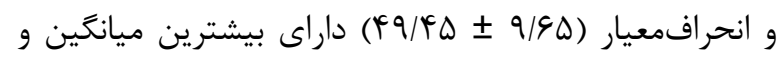
جهت

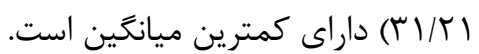

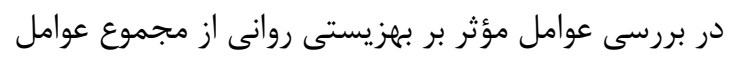

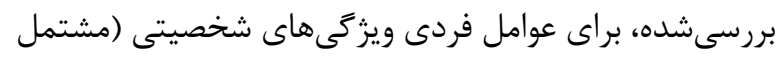

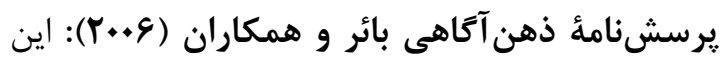

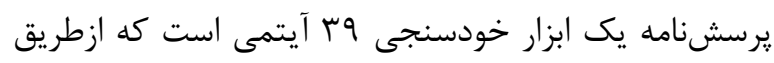

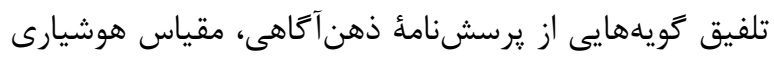

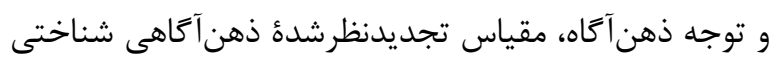

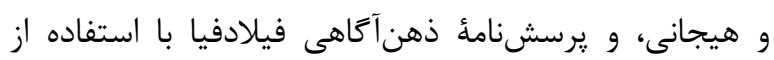

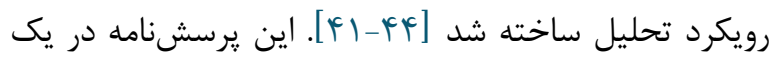
طيف ليكرت ه كزينهاى تكميل مىشود. بر اين اساس كزئه

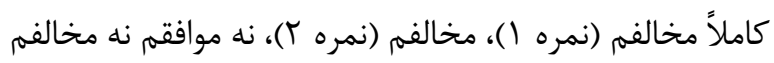

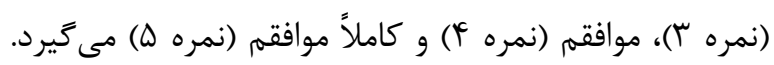

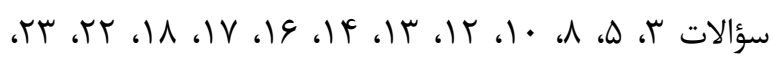

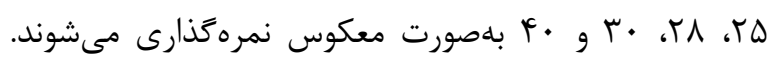

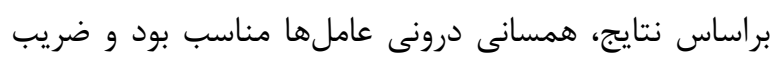

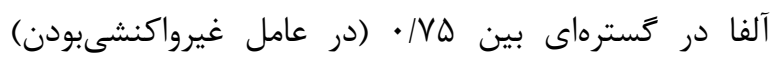

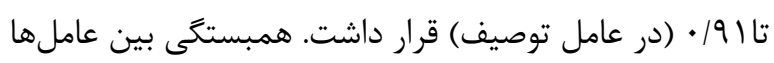

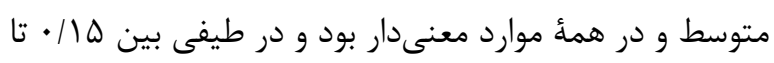

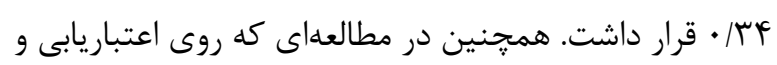

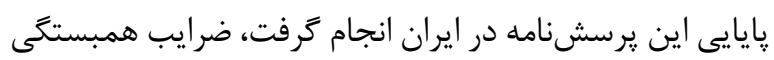

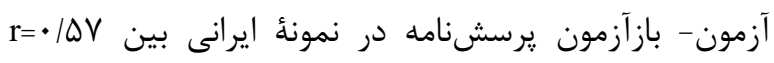

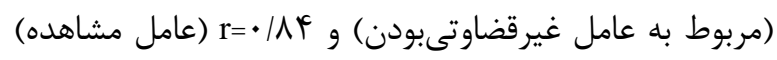

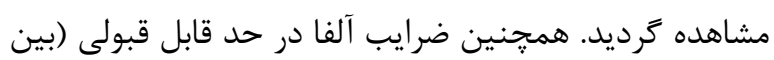

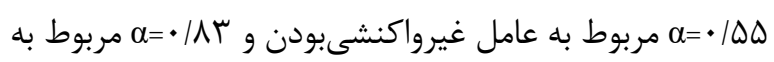
عامل توصيف) به دست آمد.

\section{يرسشنامئ حمايت اجتماعى زيمت و همكاران}

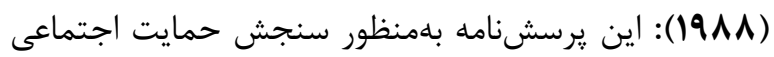

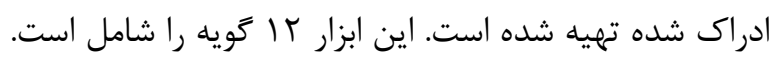

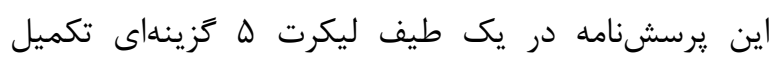
مىشود. بر اين اساس گزينهُ كاملاً مخالفم (نمره ())، مخالفم

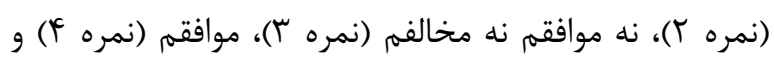

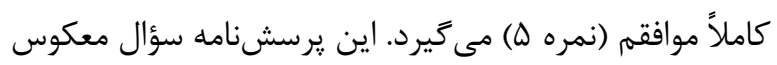

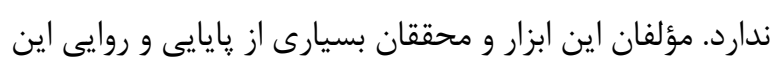

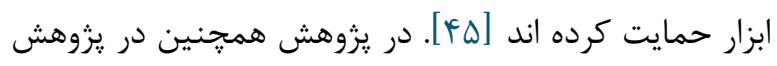

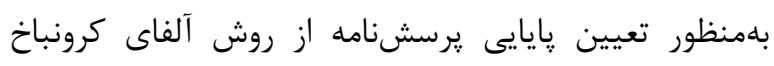

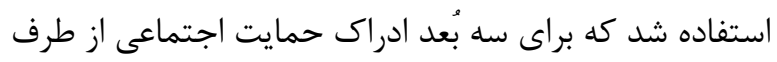

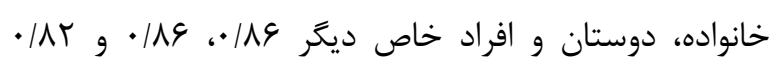

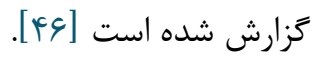

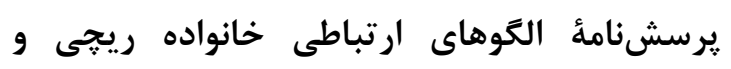

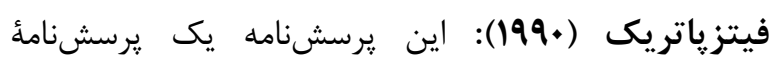


مريم سليمان فرخ و على دلاور

بر ه بُعد روانرنجورخويى، برونَرايى، گَشودَى به تجربه، عوامل خانوادَى، الكوهاى ارتباطى خانواده مشتمل بر Y بعد

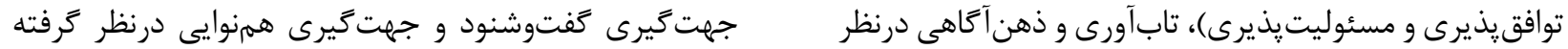

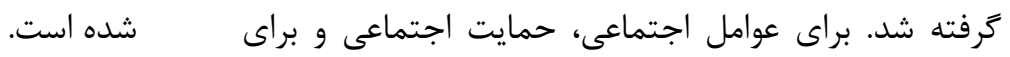

جدول ا. آمار توصيفى نمرات متغيرهاى تحقيق

\begin{tabular}{|c|c|c|c|c|c|}
\hline استاندارد انحراف & ميانگين & بيشترين & كمترين & تعداد & منبع متغير \\
\hline$\Delta / V r$ & $\Delta S / Q$. & $\checkmark \cdot$ & $i \Delta$ & $r .$. & بهزيستى روانشناختى \\
\hline$\Delta / \widetilde{Q}$ & re/Vq & $4 q$ & rt & $r .$. & روانرنجورى \\
\hline$\Delta / \Delta V$ & rN/VY & Qr & $r \Delta$ & $r \cdot$. & برون گرايى \\
\hline$\Delta / / F$ & re/r^ & $\Delta \cdot$ & r & $r \cdot$. & ويزگى هاى شخصيتى \\
\hline D/FT & $r q / \uparrow \Delta$ & Qr & re & $r \cdot$. & توافقيذيرى \\
\hline $9 / 99$ & $F / / \wedge \Delta$ & 4. & re & $r .$. & باوجدانى \\
\hline $10 / 9 \Delta$ & $\Lambda V / F \mathcal{F}$ & ITS & $\Delta \cdot$ & $r .$. & تاب آورى \\
\hline $9 / .9$ & $119 / 48$ & lrk & 91 & $r .$. & ذهن آكَاهى \\
\hline$\Lambda / r \Lambda$ & $|F| / 11$ & 4. & $r \cdot$ & $r \cdot$. & حمايت اجتماعى \\
\hline $9 / 9 \Delta$ & $F q / F \Delta$ & $\checkmark \cdot$ & rq & $r \cdots$ & \multirow{2}{*}{ الكوهاى ارتباطى خانواده } \\
\hline$N / I^{F}$ & $|r| / r)$ & QI & 11 & $r \cdot$. & \\
\hline
\end{tabular}

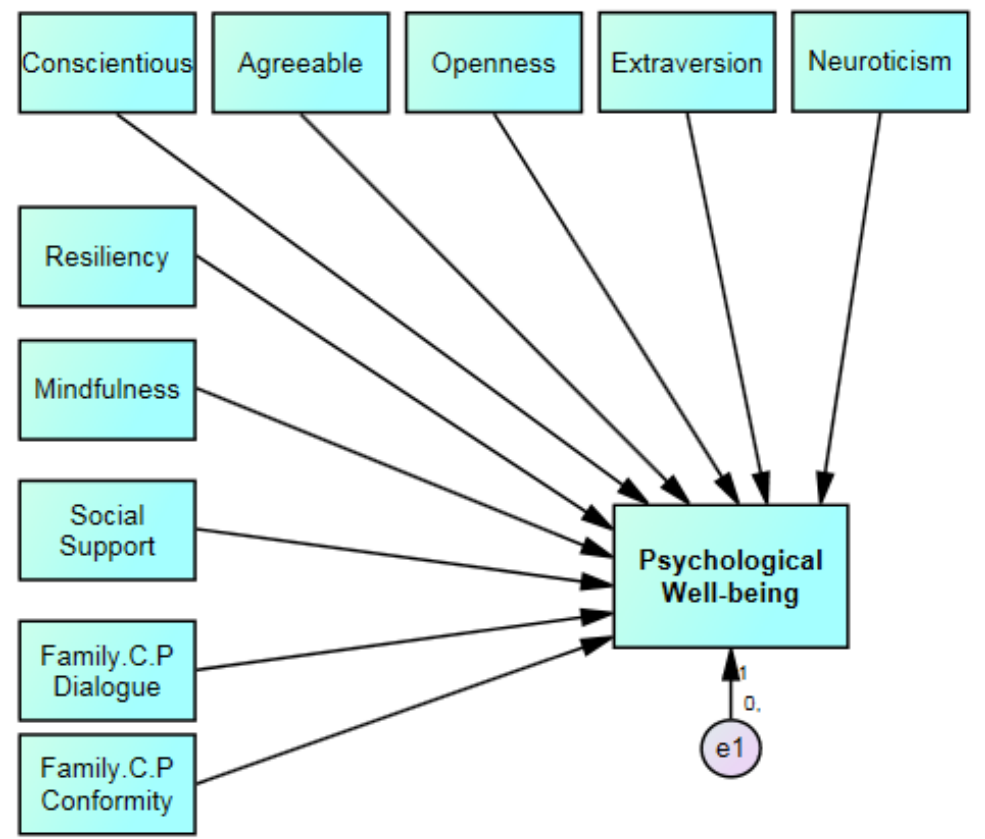

تصوير r. مدل مفروض عوامل فردى، خانوادگى و اجتماعى مؤثر بر بهزيستى روانى 
دست آمده است. در نهايت اين اعداد نشان مىدهند كه مدل درنظر ترفته شده با مدل نظرى تطبيق مناسبى نداشته است.

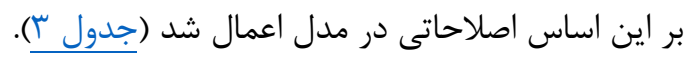
مجذور خى بر درجه آزادى در مدل برآورد شده

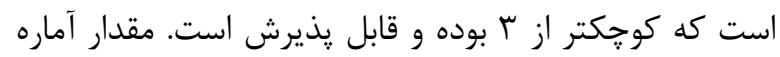

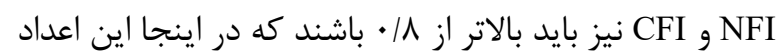

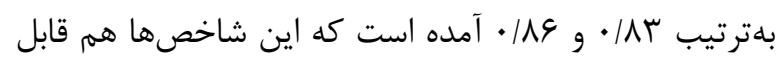

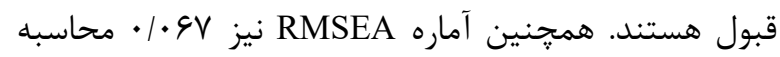

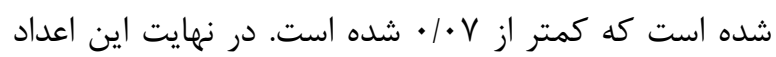

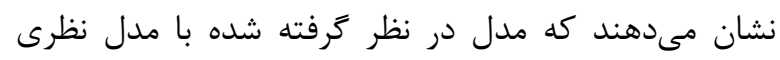
تطبيق مناسبى ييدا كرده است.

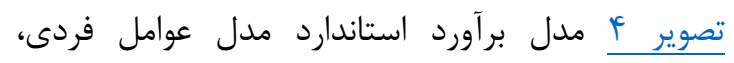

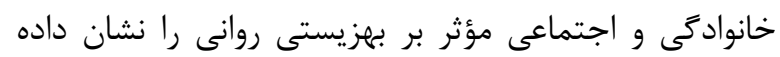

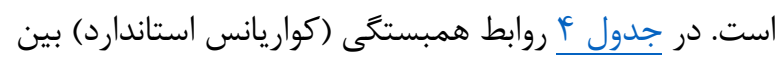
مؤلفهها و متغيرهاى يزوهش كه در اصلاحات لحاظ شده بود

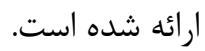

قبل از بررسى نتايج برآورد مدل، بررسى برازش مدل

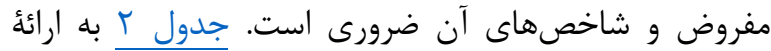
شاخصهاى برازش مدل مربوطه يرداخته است. علت استفاده

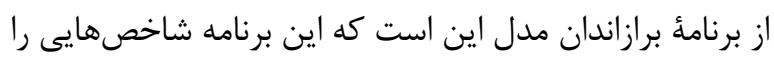

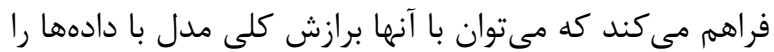

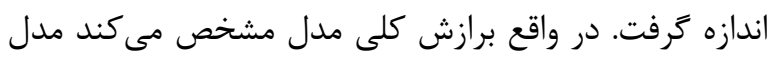

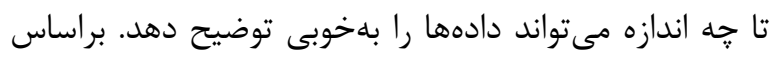

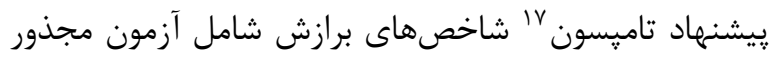

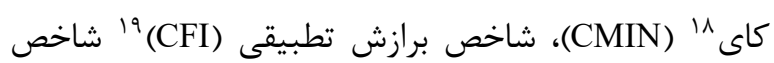

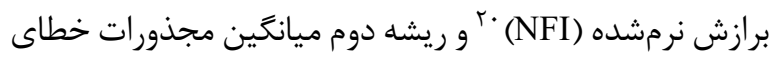

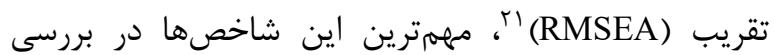

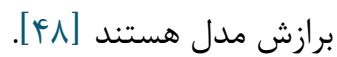

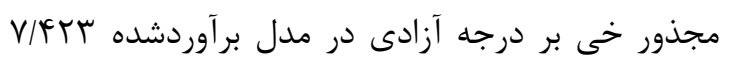

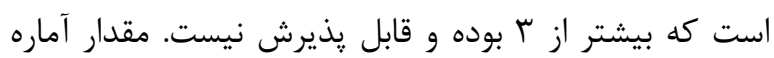

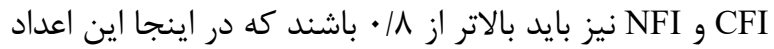

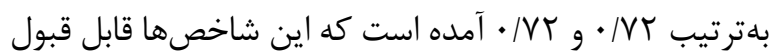

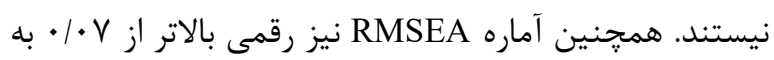

جدول r. شاخصهاى برازش مدل عوامل فردى، خانوادتى و اجتماعى مؤثر بر بهزيستى روانى

\begin{tabular}{|c|c|c|c|c|c|}
\hline نتيجه & مقدار قابل قبول & مدل استقلال & مدل اشباع & مدل مفروض & شاخص \\
\hline- & - & rt & vV & rr & NPAR \\
\hline- & - & NTN/৭9T & $\cdot / \cdots$ & $r \mu F / \cdot r \Delta$ & $\mathbf{X}^{2}$ \\
\hline- & - & $\Delta \Delta$ & . & Fa & df \\
\hline قابل قبول & كو קكتر از ץ & $|Q| \cdot V r$ & - & V/FTr & $\mathrm{X}^{2} / \mathrm{df}$ \\
\hline قابل قبول & بزركتر از A|. & $\cdot \cdots$ & 1 & $\cdot / V T$ & CFI \\
\hline قابل قبول & بزركتر از ه| . & $\cdot \cdots$ & 1 & ./VIV & NFI \\
\hline قابل قبول & بزركتر از ه|. & $\cdot / \cdots$ & 1 &. & IFI \\
\hline قابل قبول & $\cdot / \cdot V$ & $\cdot / r I V$ & - & . MIT & RMSEA \\
\hline
\end{tabular}

${ }^{20}$. Normed Fit Index

${ }^{21}$. Root Mean Square Error of Approximation
17. Thompson
18. The Chi Square Test $\left(\chi^{2}\right)$
19. Comparative Fit Index 


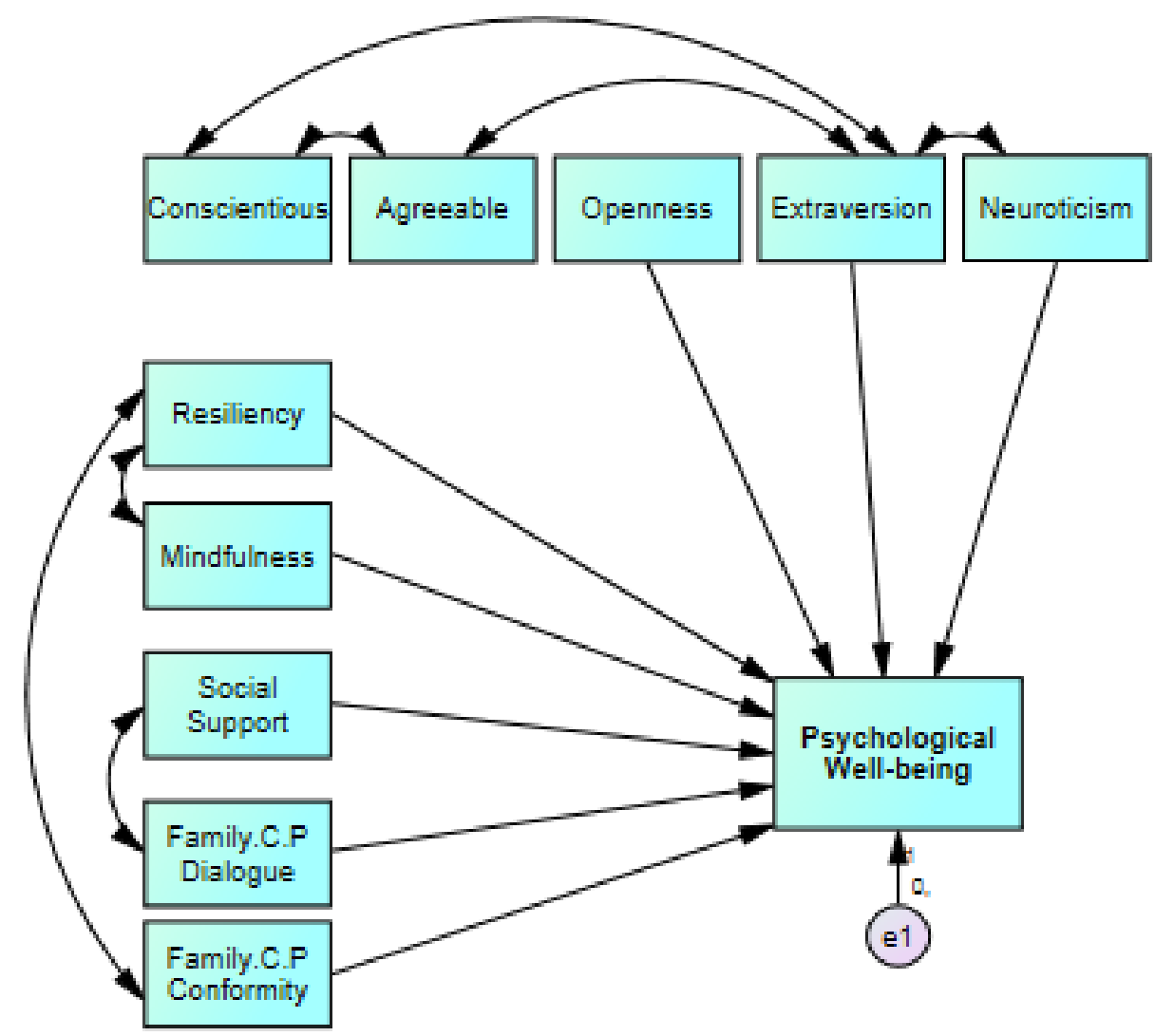

تصوير r. مدل اصلاحشدهُ عوامل فردى، خانوادكى و اجتماعى مؤثر بر بهزيستى روانى

جدول س. شاخصهاى برازش مدل اصلاح شده عوامل فردى، خانوادتى و اجتماعى مؤثر بر بهزيستى روانى

\begin{tabular}{|c|c|c|c|c|c|}
\hline نتيجه & مقدار قابل قبول & مدل استقلال & مدل اشباع & مدل مفروض & شاخص \\
\hline- & - & tr & v & rv & NPAR \\
\hline- & - & NTN/৭৭r & $\cdot / \cdots$ & W/Ak. & $X^{2}$ \\
\hline- & - & $\Delta \Delta$ & · & r. & df \\
\hline قابل قبول & كو ֶکكتر از ץ & $\mid Q / \cdot V r$ & - & r/q4G & $\mathrm{X}^{2} / \mathrm{df}$ \\
\hline قابل قبول & بزرگتر از \| • & $\cdot 1 \cdots$ & 1 & $\cdot / 9 \Delta V$ & CFI \\
\hline قابل قبول & بزرگتر از \| • & $\cdot / \cdots$ & 1 & $\cdot|\Lambda \mu|$ & ${ }^{22} \mathrm{NFI}$ \\
\hline قابل قبول & بزرگتر از ^| • & $\cdot / \cdots$ & 1 & 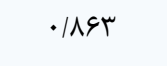 & ${ }^{23} \mathrm{IFI}$ \\
\hline قابل قبول & كوجكتر از V•• • & $\cdot / 4 I V$ & - & $.1 .9 V$ & RMSEA \\
\hline
\end{tabular}

22. Normed Fit Index (NFI)

23. Incremantal Fit Index (IFI)

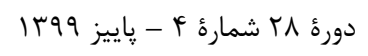




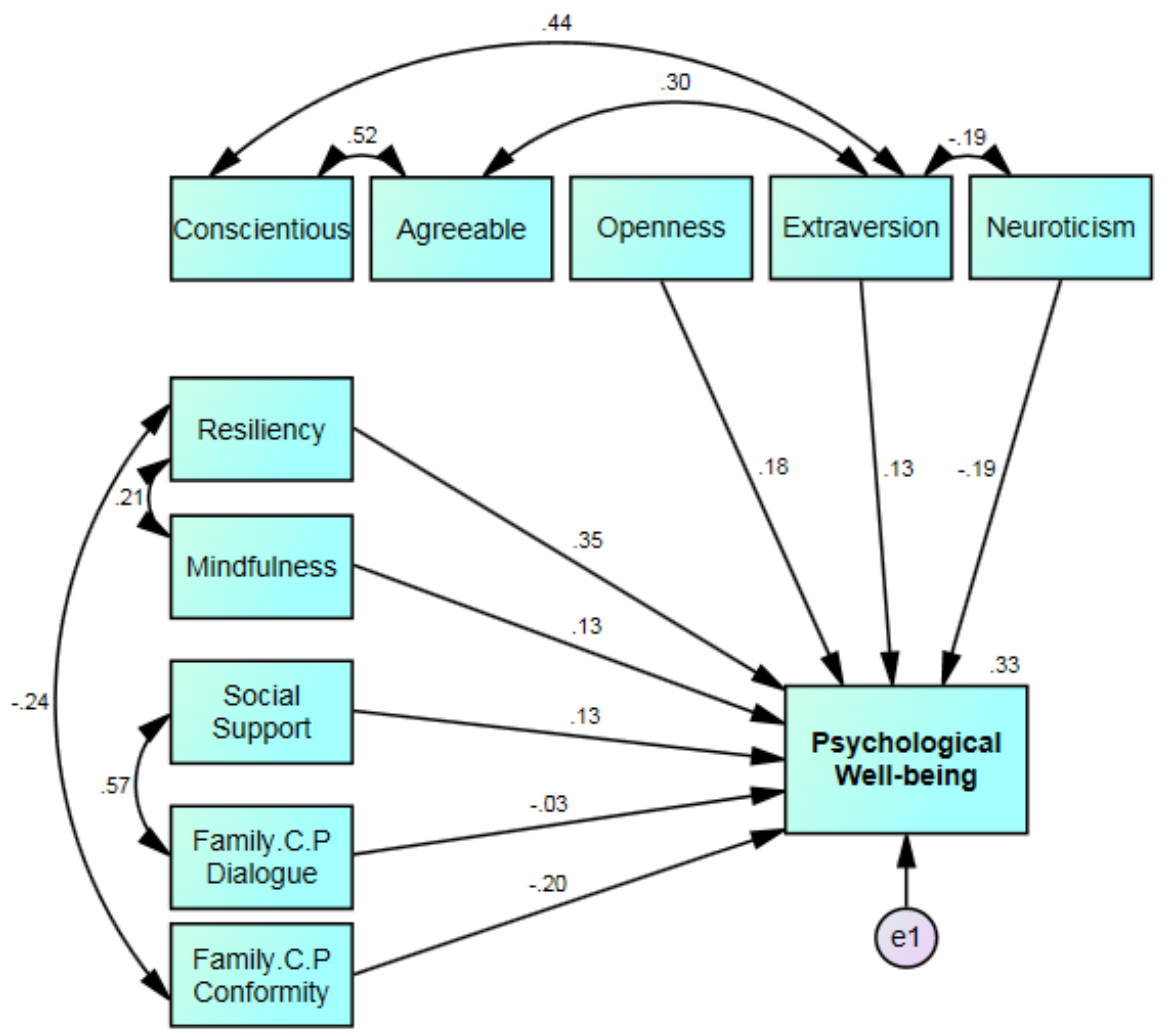

تصوير F. مدل بر آورد استاندارد مدل عوامل فردى، خانوادكى و اجتماعى مؤثر بر بهز يستى روانى

جدول F. روابط همبستتى استاندارد بين متغيرهاى ييشبين

\begin{tabular}{|c|c|c|c|c|c|c|}
\hline معنى سطارى & حد بالا & حد يايين & بر آورد & تغيير & & \\
\hline$\cdot 1 \cdot \cdot 1$ & . IGFT & $\cdot / \& \wedge \Lambda$ & $\cdot|\Delta V|$ & الكوى كفتوشنود & $\leftarrow \rightarrow$ & حمايت اجتماعى \\
\hline$\cdot 1 \cdot \cdot 1$ & -.1148 & $-\cdot|M F|$ &.$- /$ TFF & الكَوى همنوايى & $\leftarrow \rightarrow$ & تابآورى \\
\hline$\cdot 1 \cdot \cdot 1$ & $\cdot / 499$ & r & $\cdot / 411$ & ذهن آكَاهى & $\leftrightarrow \rightarrow$ & تابآورى \\
\hline$\cdot 1 \cdot r$ & -.1 .91 & $-\cdot / T V V$ & $-\cdot / 1 \wedge \Delta$ & روانرنجورى & $\leftarrow \rightarrow$ & برون گرايى \\
\hline$\cdot 1 \cdot \cdot 1$ & $\cdot / 091$ & $\cdot / \mathcal{A} \Delta \varphi$ & $\cdot \mid \Delta T F$ & مسئوليتيذيرى & $\leftarrow \rightarrow$ & توافقيذيرى \\
\hline$\cdot 1 \cdot \cdot 1$ & $\cdot / \Delta T \Lambda$ & •/rur & . MFt & برون گرايى & $\leftarrow \rightarrow$ & مسئوليت پذيرى \\
\hline$\cdot 1 \cdot \cdot 1$ & $\cdot / 4 \cdot 1$ & $\cdot . M I F$ & $\cdot \pi \cdot r$ & برون گرايى & $\leftarrow \rightarrow$ & توافقيذيرى \\
\hline
\end{tabular}

مسئوليت ڤِيرى، مسئوليتيذيرى و برون گرايى و توافقيذيرى و برون

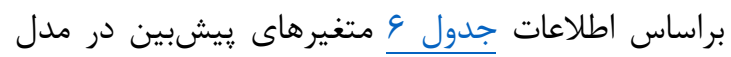

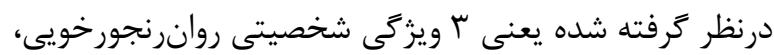

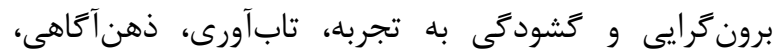

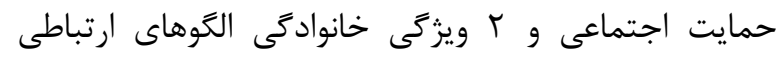

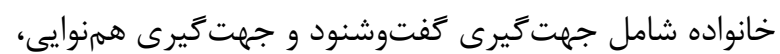

جدول ه نشان داد كه بين حمايت اجتماعى و الكوى ارتباطى كفتوشنود در خانواده رابطهُ مثبت و مستقيمى وجود دارد. بين تابآورى و الگوى ارتباطى همنوايى خانواده رابطه

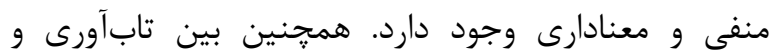
ذهن آكاهى رابطهُ مثبت و معنادارى مشاهده شده است. در بين عوامل شخصيتى نيز برون گرايى با روانرنجورى رابطهُ منفى و

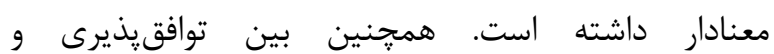




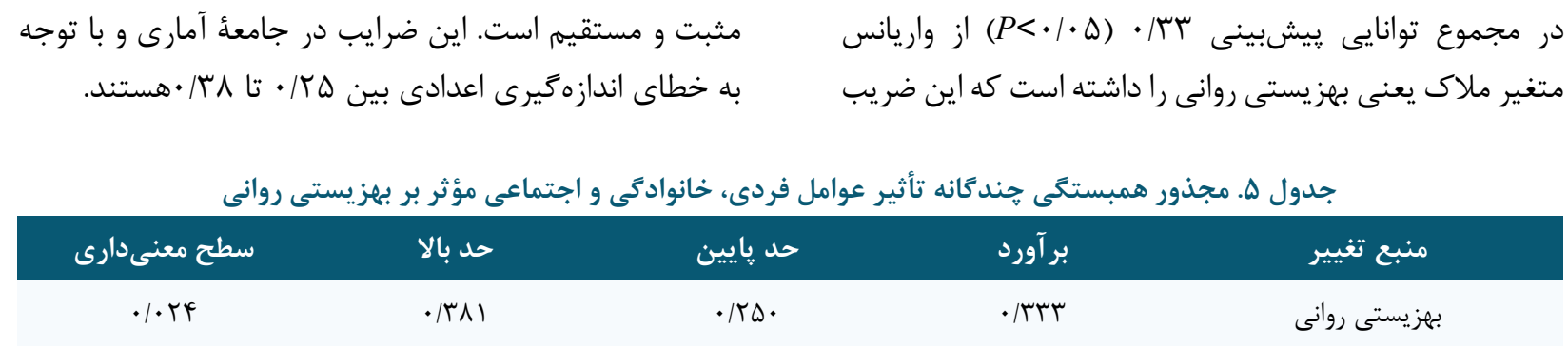

جدول 9. شاخصهاى روابط استاندارد در مدل اصلاح شده

\begin{tabular}{|c|c|c|c|c|c|c|}
\hline معنى دارى & حدبالا & حد يايين & بر آورد & بيش بين & \multicolumn{2}{|c|}{ متغير ِيش بين } \\
\hline$\cdot / \cdot \cdot 1$ & . ITVV & . & $\cdot|| \wedge \mid$ & بازبودن & \multirow{3}{*}{ عوامل شخصيتى } & \multirow{5}{*}{ عوامل فردى } \\
\hline $.1 \cdot 9 r$ & . ITHA & $\cdot 1 \cdot 10$ & $\cdot / / r$. & برون & & \\
\hline$\cdot \mid \cdot \cdot 1$ & -.1 .99 & $-\cdot|r V|$ & $-\cdot / 1 \wedge 9$ & روانرنجورى & & \\
\hline$\cdot / \cdot \cdot 1$ & $.|f| f \mid$ & . MFT & . MFG & \multicolumn{2}{|c|}{ تابآورى } & \\
\hline .1 .19 & $\cdot / T I V$ & $\cdot / \cdot r q$ &.$/ I r \wedge$ & \multicolumn{2}{|c|}{ ذهن آكاهى } & \\
\hline.$/ \cdot 1$. & - KTS & $.1 \cdot 49$ & אTM & \multicolumn{2}{|c|}{ حمايت اجتماعى } & عوامل اجتماعى \\
\hline r| & $\cdot 1 \cdot \mathrm{Vq}$ & $-.|| f \mid$ & Tr. & كَفتوشنود & \multirow{2}{*}{ خانواده ارتباطى } & \multirow{2}{*}{ عوامل خانوادگى } \\
\hline$\cdot 1 \cdot \cdot 1$ & -.1 .94 & $-\cdot / r \wedge \Delta$ & -.1199 & همنوايى & & \\
\hline
\end{tabular}

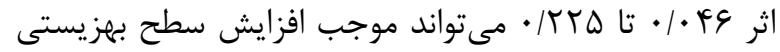
روانى بيماران مبتلا به سرطان سينه شود. نهايتاً درمورد عوامل

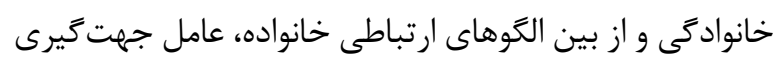

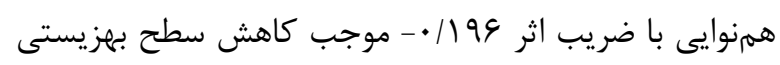

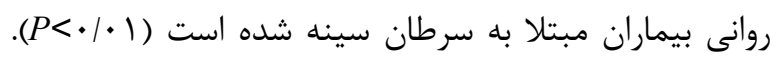

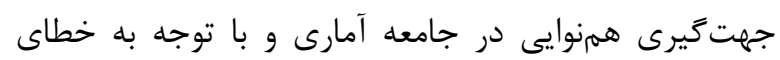

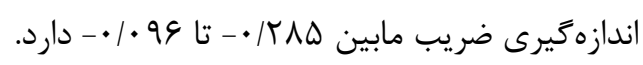

\section{بحث}

در بررسى عوامل مؤثر بر بهزيستى روانى از مجموع عوامل

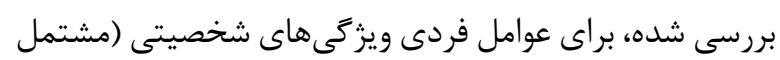

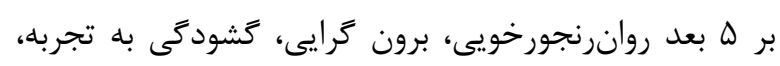

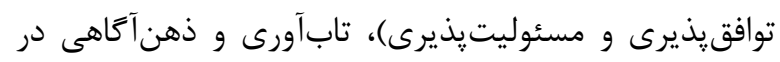
نظر گرفته شد. براى عوامل اجتماعى، حمايت اجتماعى و براى

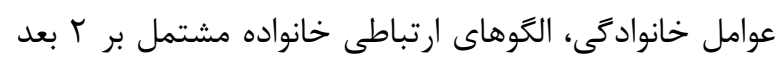
جهت گيرى كفتوشنود و جهت گيرى همنوايى در نظر گرفته شده است. بامنظور تصحيح برازش مدل دو عامل شخصيتى
جدول V نشان مى نهد در حالت استاندارد Y عامل بازبودن به تجربه و روانرنجورى از بين عوامل شخصيتى بهترتيب با لان

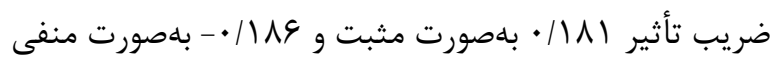
بر بهزيستى روانى بيماران مبتلا به سرطان سينه تأثير دارند

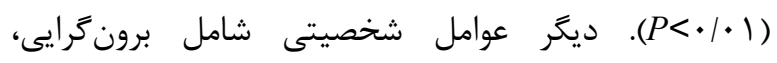
مسئوليتٍذيرى و توافتيذيرى تأثير معنادارى بر بهزيستى دئى

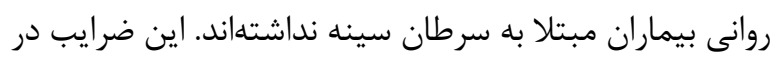

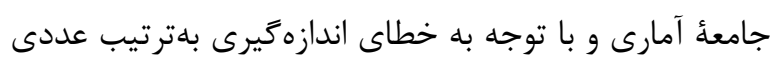

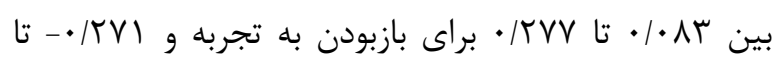

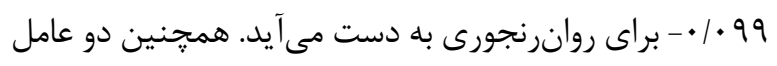
ديخر از عوامل فردى تابآورى و ذهن آتاهى نيز بهترتيب داني

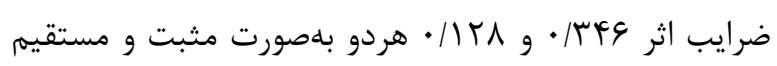
موجب افزايش سطح بهزيستى روانى بيماران مبتلا به سرطان

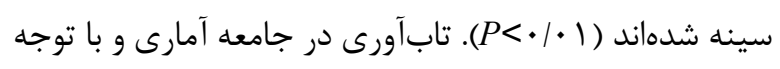

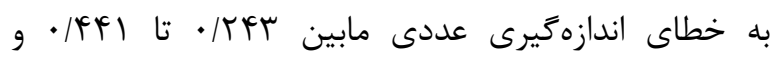

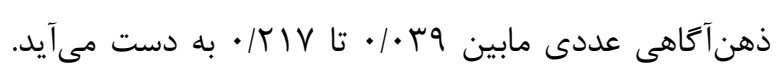

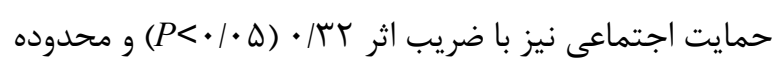


مى كنند جون اين ويزگى به آنها كمك مى كند از شرايط

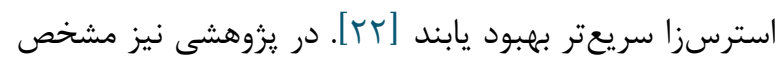

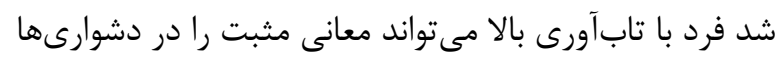

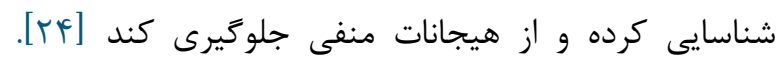

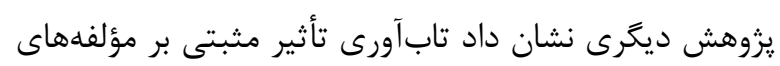

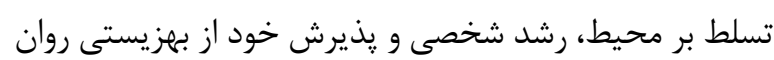

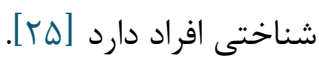

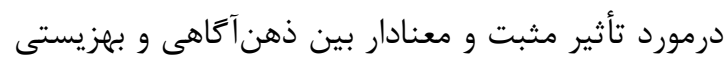

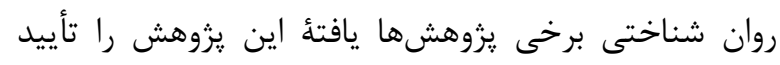

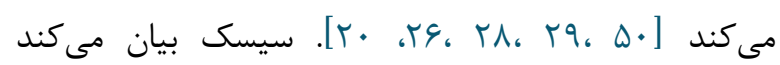

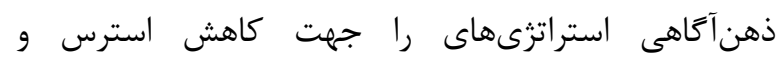

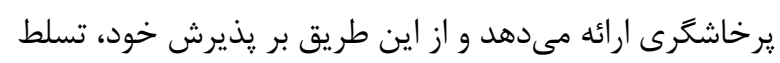

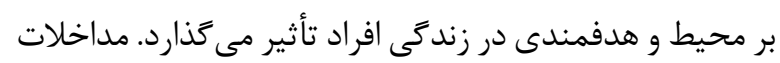

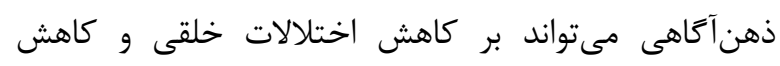

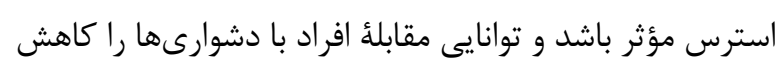

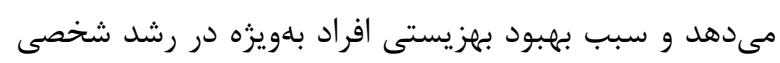

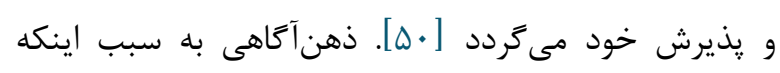

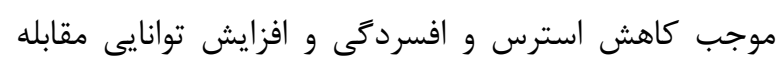

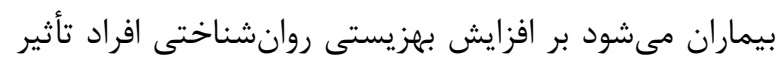

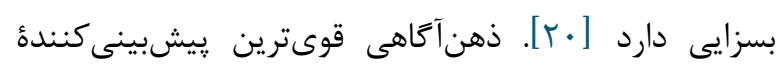

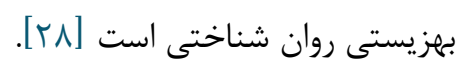

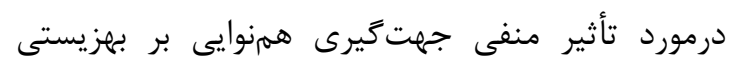

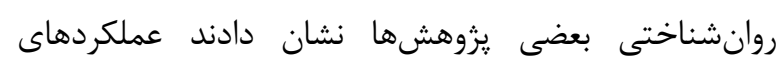

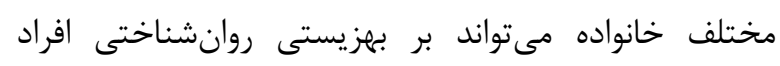

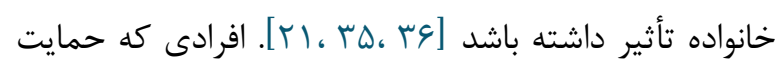

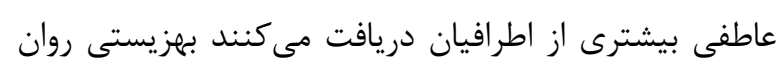

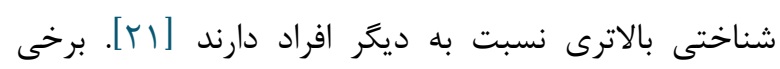
يروهشها نشان مىدهند بين متغيرهاى عملكرد خانواده با باليا

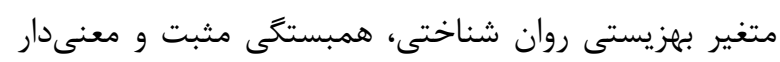

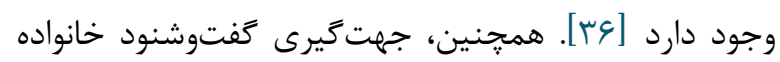

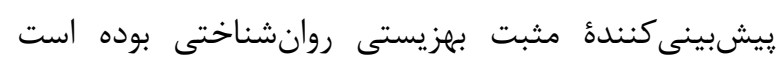

[ـo]

نهايتاً درمورد تأثير مثبت و معنادار بين حمايت اجتماعى

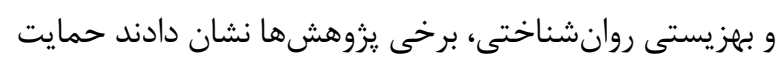

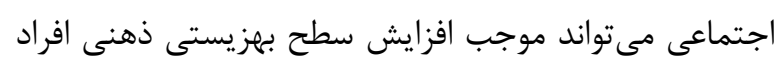

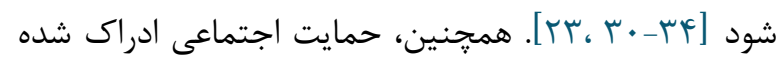

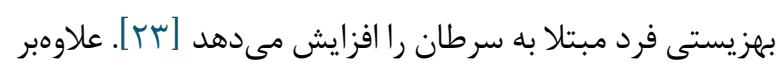

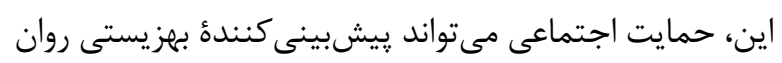

مسئوليتيذيرى و توافقيذيرى از مدل نهايى حذف شدند.

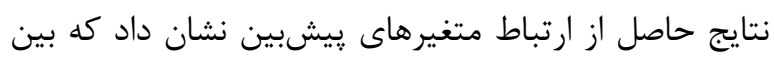

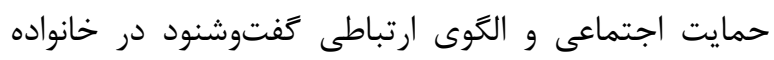

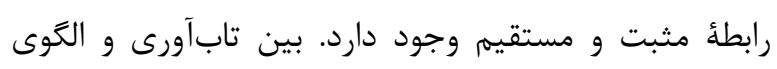

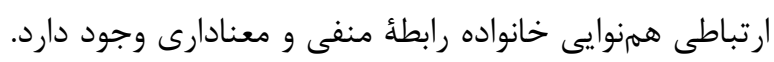

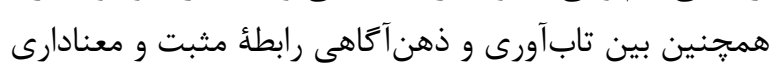

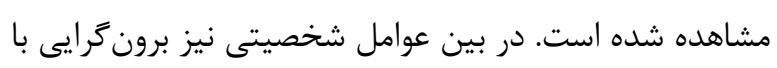

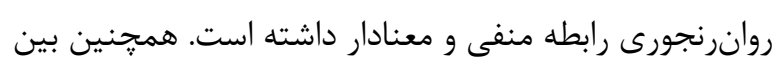

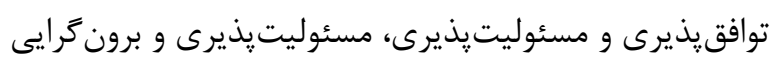

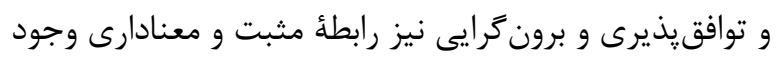

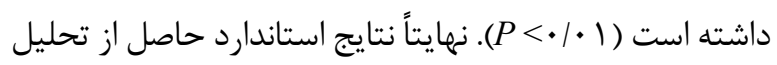

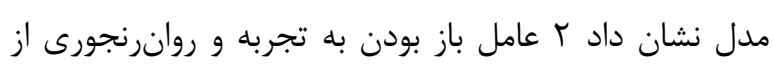

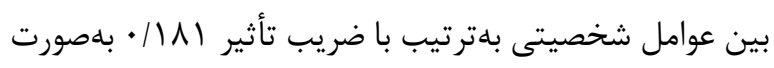

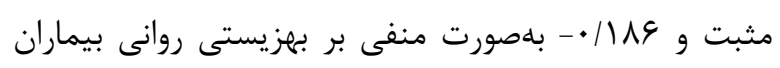

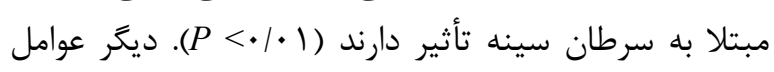

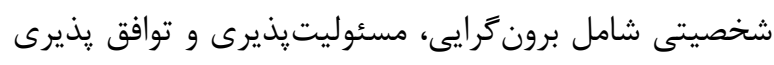

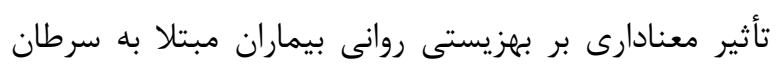

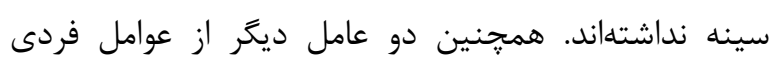

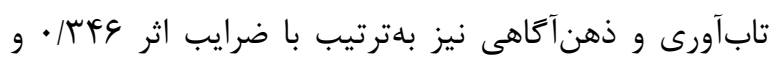

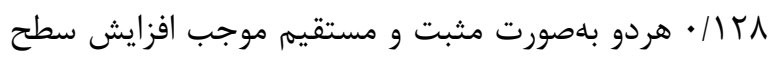

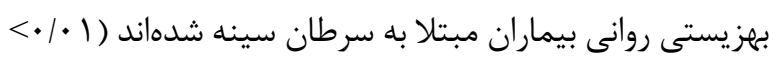

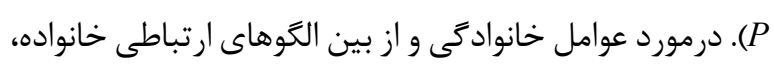

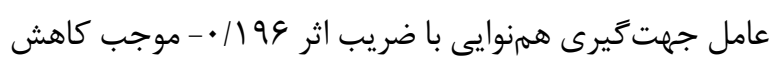

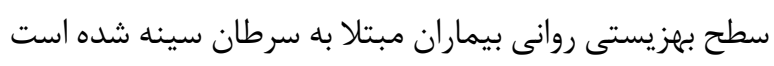
(1)

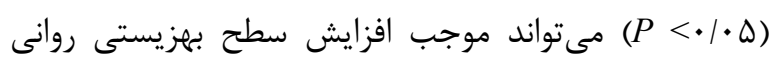
بيماران مبتلا به سرطان سينه شود.

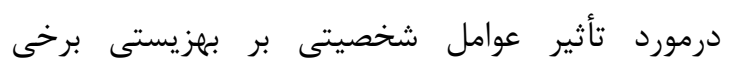

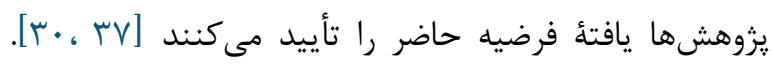

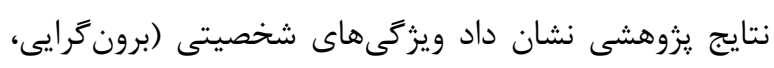

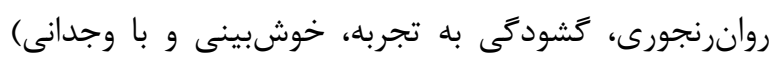

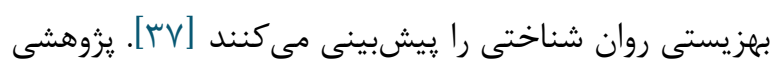

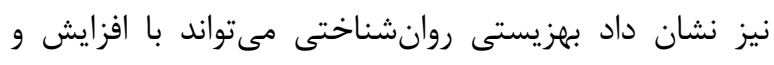
روانرنجورى كاهش يابد [Fq]

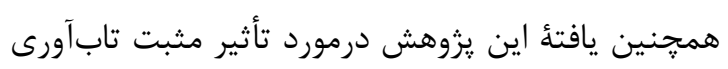

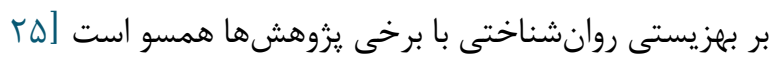

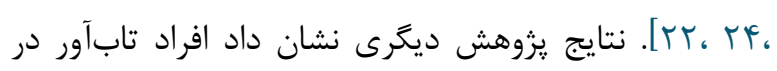

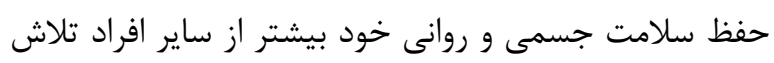


عاطفهُ منفى براساس نظريهُ بهزيستى روانشناختى (بهعنوان

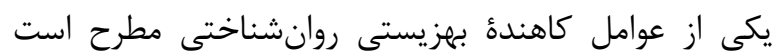

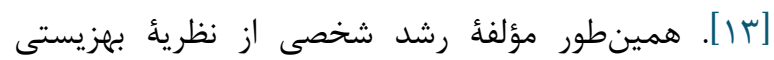

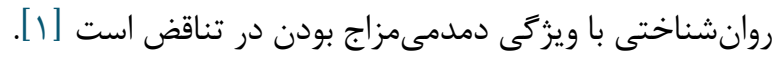

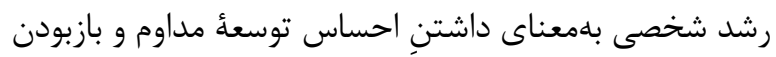
به تجربيات جديد است. به عبارتى فرد در اين حالت، براى

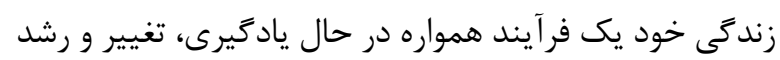

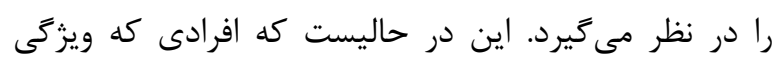
شخصيتى روانرنجورى دارند، در دنبال كردن اهداف بلندمدت دير دان

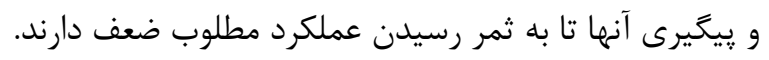

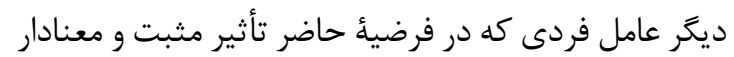

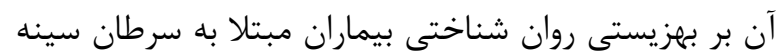

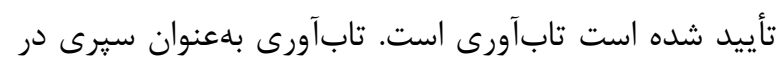

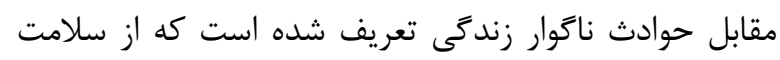
روان افراد حمايت مى كند. درمورد تأثير مثبت تابآورى بر تردان

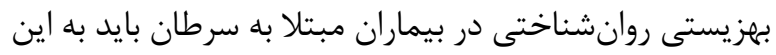

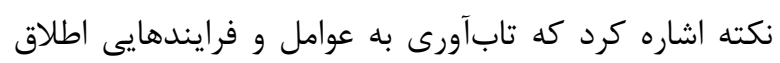
مىشود كه خط سير رشدى را از مسير رفتارهاى مشكلزا و وان

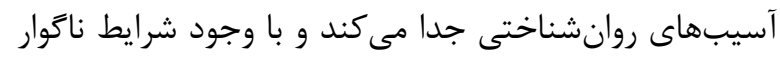

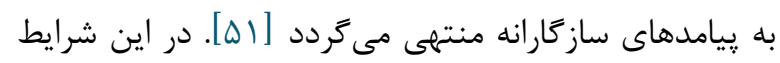

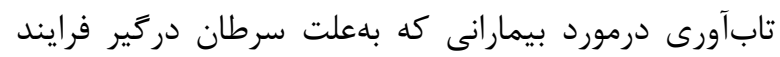
طاقتفرساى درمانهاى تهاجمى سرطان سينه مانند عمل دران دران جراحى و شيمى درمانى مىشوند مىتواند بهعنوان تهان عاملى سلى محافظتى درمقابل تهديدهاى اين بيمارى مطرح باشئ درئ

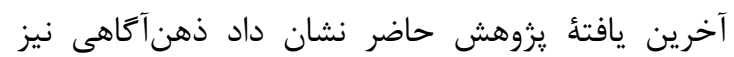

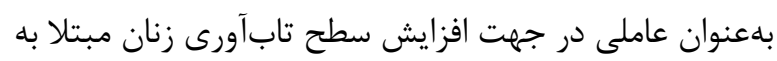

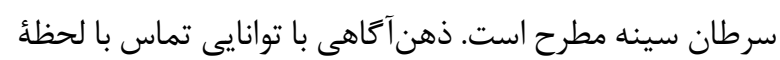
اكنون درمورد هيجانات، افكار و متغيرهاى خارجى مانند حوادث زندگَى مطرح است. ذهن آكاهى به افراد اين توانايى را

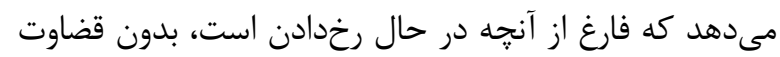

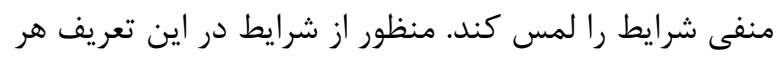

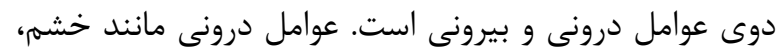

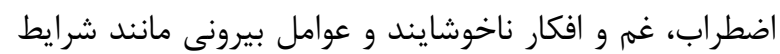

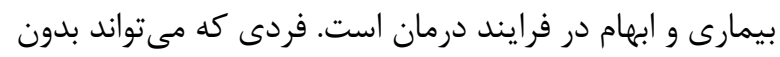

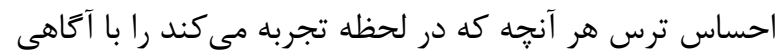
بيذيرد، خودانتقادى كمترى دارد. زنان مبتلا به به بيمارى

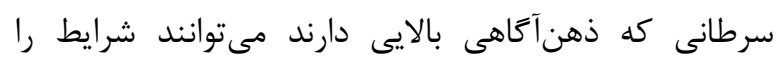
آن گونه كه هست، نه بهصورت شرايط بحرانى تجربه كنيند. در
شناختى باشد؛ همجنين اثربخشى حمايت اجتماعى توسط

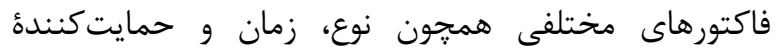

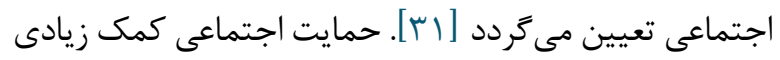

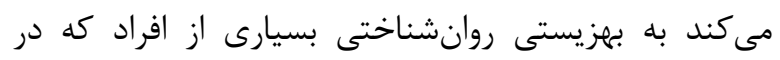

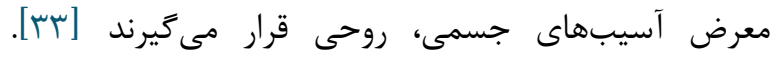
برخوردارى فرد از حمايتهاى اجتماعى خانواده، دوستان و و

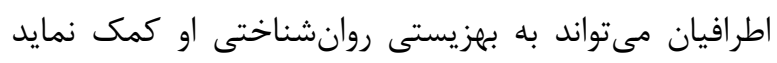
. [ry ] درمورد تأثير مستقيم گشودگى به تجربه بر بهزيستى

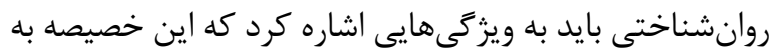

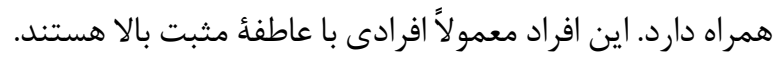

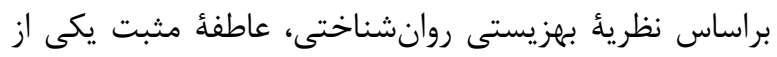

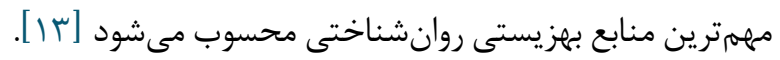

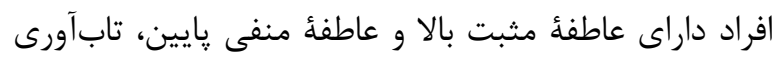

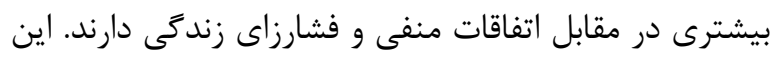

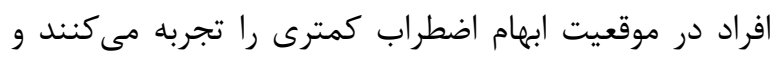

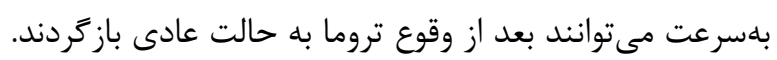

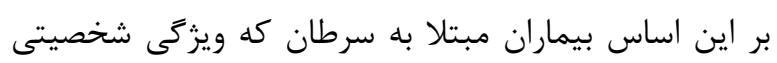

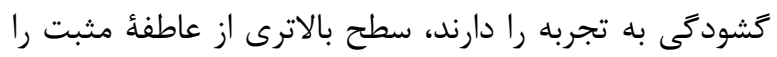

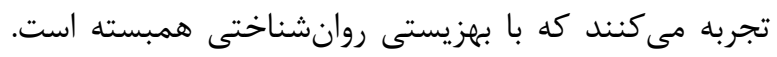

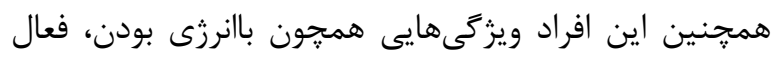

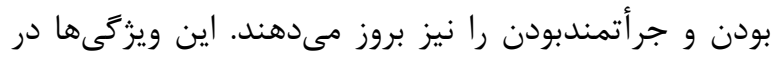

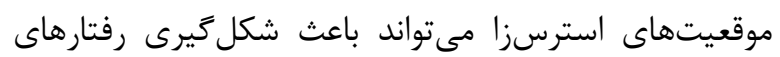

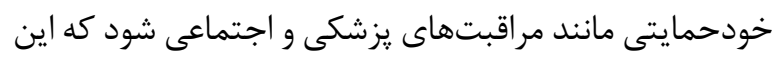

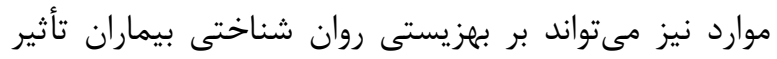

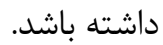

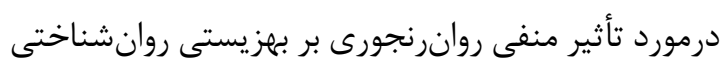

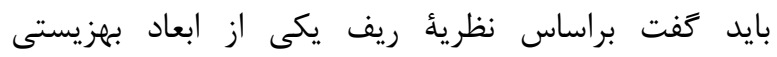

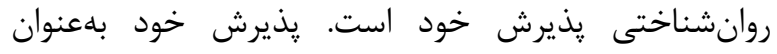

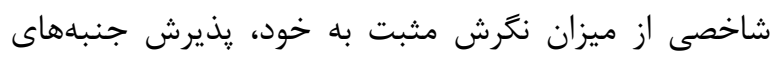

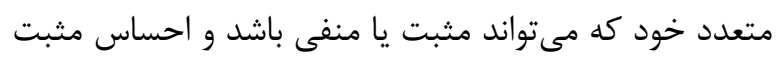

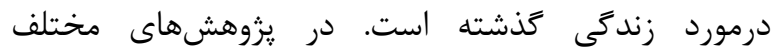
خوديذيرى بهعنوان اصلىترين عامل مؤثر در بهزيستى مطرح

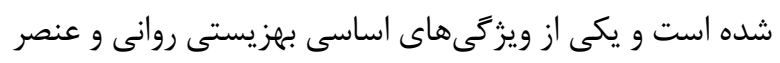

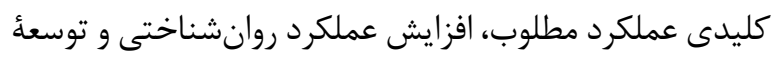

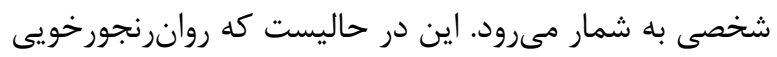

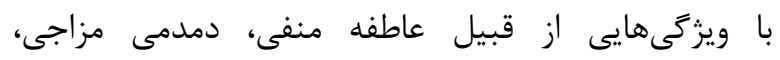

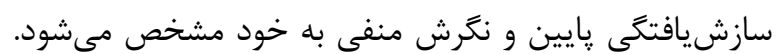


و ديكران جلوكيرى كنند كه اين عامل نيز بسيار بهتر از

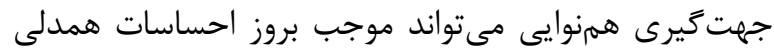
در بين افراد شود. در واقع افراد در خانوادههايى كه جهت دئ ديرى كفتوشنود دارند تشويق مىشوند درمورد آنجه در حال وقوع آنداني

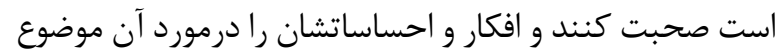

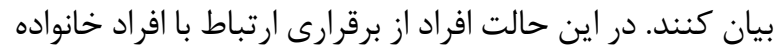

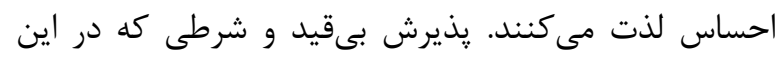

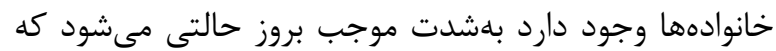

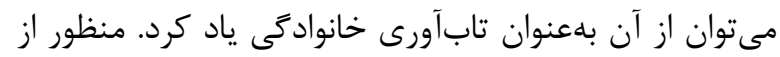

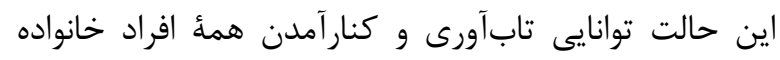
بلهنوان يك كل واحد با مشكلات بيمارى سرطان است. سوم، افراد در خانوادههايى كه جهت كيرى تَفتوشنود دارند دركيرى مخرب ارتباطى كمترى نسب به خانوادههاى با

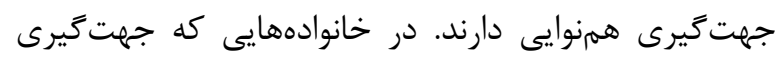
همنوايى حاكم است هيجكس جز افراد بزركتر بلى بلويزه والدين نمىتوانند براى حل مشكلات اظهارنظر كنند. در اين خانوادهها تصميم نهايى توسط يكى از والدين يا هردوى آنها كرفتئه

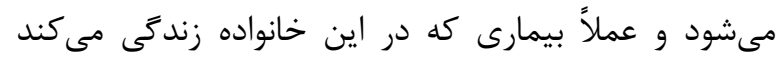
اختيار بسيار كمى درمورد روند درمان بيمارى خودش دارد اردي

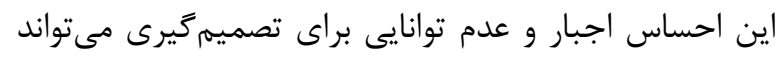

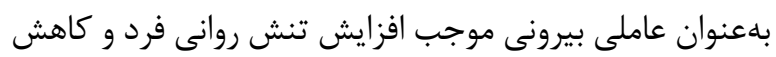
سطح بهزيستى روانشناختى او مطرح باشد.

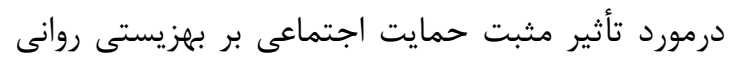

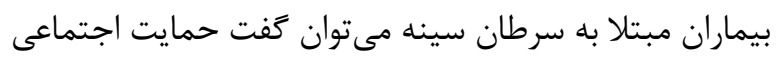
اساساً بهعنوان يكى از مهمترين عوامل بيرونى و غير فردى برى مؤثر بر بهزيستى روانشناختى مطرح است. شايد بتوان كفت

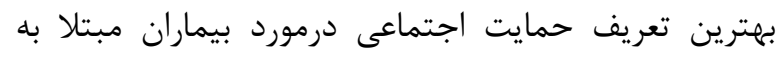
سرطان دردسترس بودن و كيفيت ارتباط با افرادى باشد كه دهريف در مواقع موردنياز، منابع حمايت را فراهم مى كنند. علاوهبر

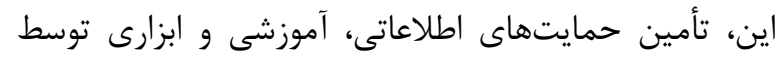

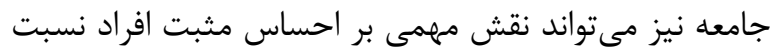

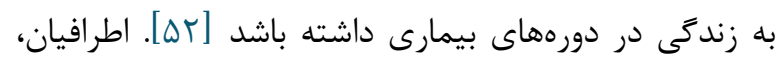

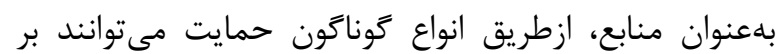

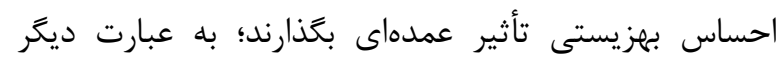

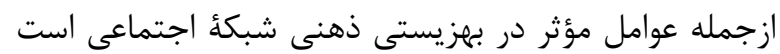

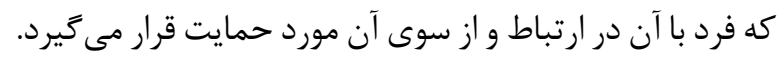

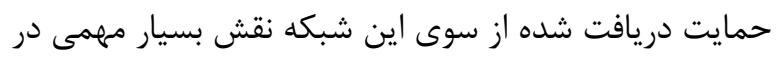
نوع كنش فرد با خود و محيط دارد [بها].
اين فرايند خودانتقادى كه بهعنوان عاملى مهمم در كاهش سطح بهزيستى روان شناختى مطرح است كاهش مى يابد و فرد

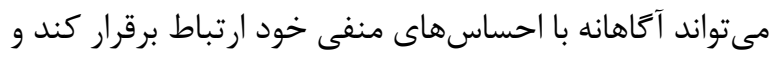

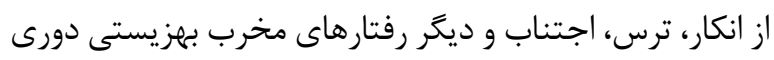
كند. همجنين ذهنآكاهى با طيف وسيعى از يِيش آيندهاى بهزيستى در ارتباط است. بهعنوان مثال هيجانات مثبت،

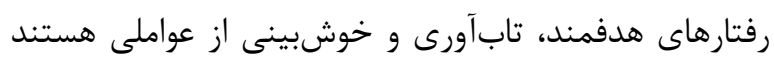

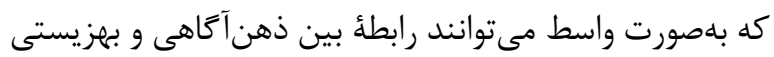
روانشناختى را در زنان مبتلا به سرطان سينه تبيين كنند.

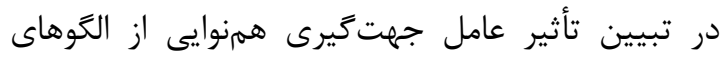

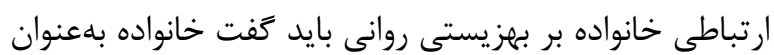

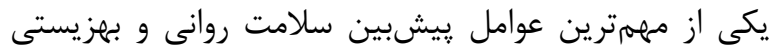

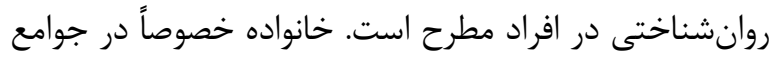

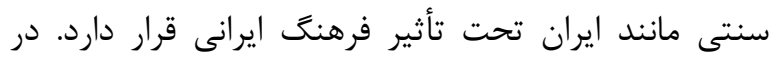
فرهنگ خانوادة ايرانى وقتى فردى از اعضاى خانواده دركير مشكل يا بيمارى مىشود، ديكر اعضاى خانواده وظيفه خود

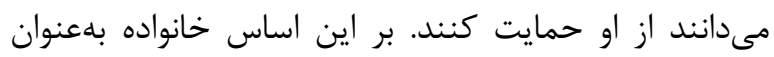
عاملى كه مىتواند فشارهاى ناشى از بيمارىهاى مختلف إنف بلويزه بيمارى هاى صعبالعلاج را در بين افراد خانواده تقسيم إنى نمايد مىتواند موجب كاهش سطح فشار روانى بر بيمار شود. نتايج مصاحبهُ يُوهشكر با برخى از بيمارانى كه بيان مى كردند

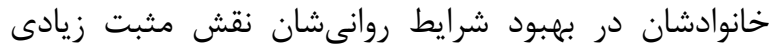

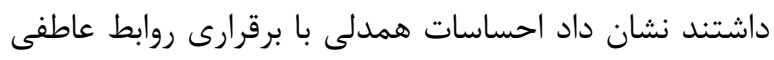

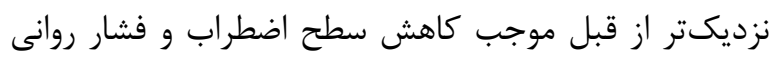

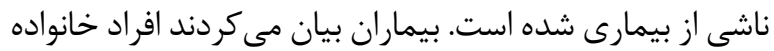

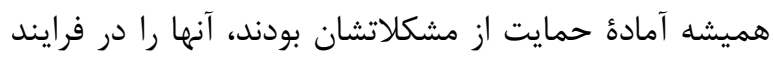

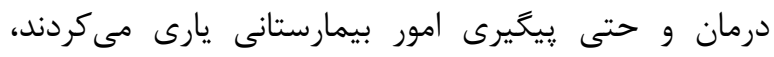

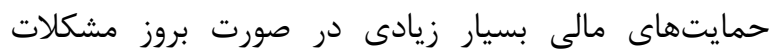

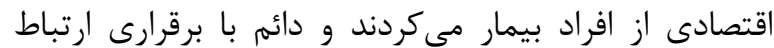

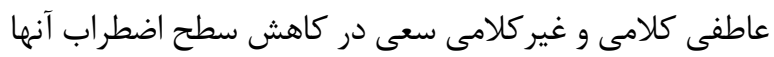
داشتند. اما جهت گيرى كَفتوشنود با بروز احساساتى مانند

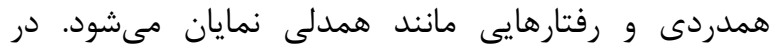

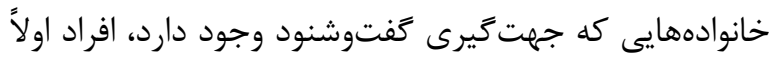

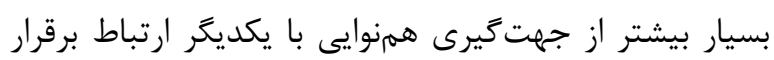

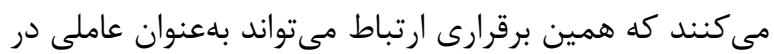
جهت بهبود وضعيت بهزيستى روانشناختى مطرح باشد. دوم،

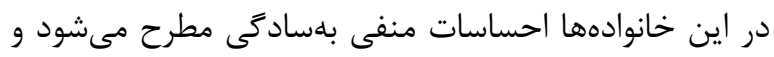
اعضاى خانواده سعى ندارند از بيان احساسات ناخوشايند خود بادي 


\section{نتيجه گيبرى}

نتايج حاصل از تحليل مدل نشان داد از بين عوامل فردى، عوامل شخصيتى بازبودن به تجربه بهطور مثبت و روانرنجورى مئ

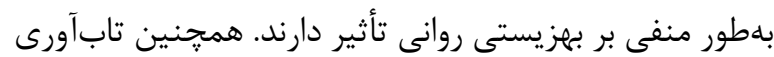
و ذهن آكاهى نيز هردو بهطور مثبت موجب افزايش بهزيستى بهى لهنى

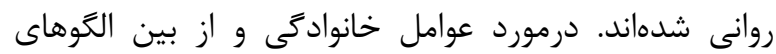
ارتباطى خانواده، عامل جهت ريرى همنوايى موجب كاهش

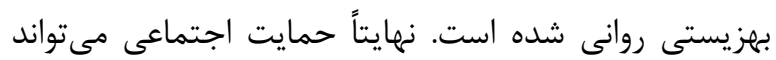
موجب افزايش بهزيستى روانى شود.

\section{سياسگز ارى}

از تمامى بيمارانى كه باوجود مشكلات فراوان، صبورانه در اين مطالعه شركت نمودند تشكر و قدردانى مى كنيم.

تعارض در منافع

بين نويسندكان هيج گونه تعارضى در منافع وجود ندارد

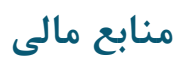

منابع مالى اين مطالعه توسط نويسندكان تامين شده است.

\section{References}

1. Monfared A, Pakseresht S, Ghanbari Khanghah A, Atrkar-Roshan Z. Health-Related Quality of Life and its related factors among women with breast cancer. J Holis Nurs Midwifery. 2013; 23(2):52-62.

2. Momeni T, Musarezaie A, Karimian J, Ebrahimi A. The relationship between spiritual well-being and depression in Iranian breast cancer patients. Health Inform Manag. 2011; 8(8):1007-16.

3. Mardani Hamule M, Shahraky Vahed A. The Assessment of Relationship between Mental Health and Quality of Life in Cancer Patients. Sci J Hamadan Univ Med Sci. 2009; 16(2):33-8.

4. Matsushita T, Matsushima E, Maruyama M. Psychological state, quality of life, and coping style in patients with digestive cancer. Gen Hospital Psych. 2005; 27(2):125-32 [DOI:10.1016/i.genhosppsych.2004.10.006] [PMID]

5. Bekelman DB, Dy SM, Becker DM, Wittstein IS, Hendricks DE, Yamashita TE, et al. Spiritual wellbeing and depression in patients with heart failure. $\mathrm{J}$ General Inter Med. 2007; 22(4):470-7.
منابع حمايت اجتماعى در اين يزوهش سه منبع خانواده، افراد مهم و دوستان بودند. حضور در ميان دوستان، خانواده و سايرين باعث كسترش روابط اجتماعى مىشود و بر ادراى

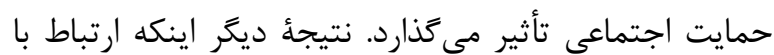
دوستان، خانواده، خويشاوندان و سايرين در ميان بيماران داراى اهميت است. اين در حاليست كه يكى از مؤلفههاى بهزيستى روانشناختى در نظريئ Ryff تسلط بر محيط است. منظور از تسلط بر محيط در اين تعريف صرفاً تسلط فيزيكى نيست، بلكه دئه تسلط ذهنى نيز مطرح است. بر اين اساس ادراك فرد از تسلط بر محيط در اين حالت مطرح است. اين بعد از تسلط بر محيط دمان بيشتر بر جنبdهاى بينشخصى روابط اشاره دارد و بسيار به

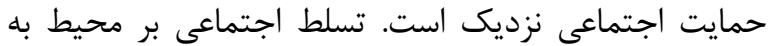
انتخاب و كنترل محيط اطراف ازطريق اعمال ذهنى اشاره دارد. درحالى كه سطح بالاى تسلط بر محيط، توانايى بالاى فرد را در

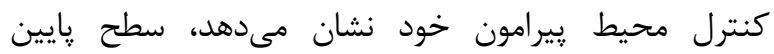
نشاندهنده عدم توانايى كنترل شرايط محيط و زندگى است. افراد بالغ بهطور كلى قادر به تعامل و برقرارى ارتباط با افراد

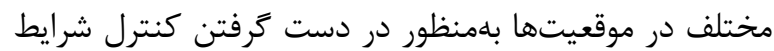
دشوار هستند. بر اين اساس افرادى كه داراى شبكة حمايتى مورى اجتماعى گسترده هستند در مؤلفئ تسلط بر محيط بهزيستى إنى روانشناختى نمرات بالاترى كسب مى كنند.

[DOI:10.1007/s11606-006-0044-9] [PMCID]

6. Kamian S, Taghdisi MH, Azam K, Estebsari F. Evaluating Effectiveness of Spiritual Health Education on Increasing Hope among Breast Cancer Patients. Iran J Health Educ Health Prom. 2014; 2(3):208-14.

7. Hayati F, Shahsavari A, Mahmodi M. relation psychic convenience with individual factors of patients with breast cancer in hospitals of Tehran University of Medical Science. J Iran Breast Disease. 2009; 2(1):238.

8. Kaliampos A, Roussi P. Religious beliefs, coping, and psychological well-being among Greek cancer patients. J Health Psych. 2015; (1):1-11.

9. Yeung $\mathrm{NC}, \mathrm{Lu}$ Q. Perceived stress as a mediator between social support and posttraumatic growth among Chinese American breast cancer survivors. Cancer Nurs. 2018; (41):53-61. [DOI:10.1097/NCC.0000000000000422] [PMID] [PMCID] 
9 تأثير عوامل فردى، خانوادگى و اجتماعى در بهزيستى روانشناختى بيماران

10. Castro E, Ponciano C, Meneghetti B. Quality of Life, Self-Efficacy and Psychological Well-Being in Brazilian Adults with Cancer: A Longitudinal Study. Sci Res. 2012; 4(3):304-9. [DOI:10.4236/psych.2012.34043]

11. Vin-Raviv N. Racial disparities in posttraumatic stress after diagnosis of localized breast cancer: the BQUAL study. J Natl Cancer Inst. 2013; 105(8):563-72. [DOI:10.1093/jnci/djt024] [PMID] [PMCID]

12. Pintado S. Self-concept and emotional well-being in patients with breast cancer. Revista Iberoamericana Psicología Salud. 2017; 8(2): 76-84. [DOI:10.23923/j.rips.2017.08.007]

13. Seligman M. Flourish: A visionary new understanding of happiness and well-being. New York: Free Press; 2011.

14. Kun A, Balogh P, Krasz KG. Development of the work-related well-being questionnaire based on Seligman's PERMA model. Soc Manag Sci. 2017; (25):56-63. [DOI:10.3311/PPso.9326]

15. Seligman ME. Fundamental assumptions. Psychologist. 2003 Mar;16(3):126.

16. Hefferon K, Boniwell I. Pozitif psikoloji kuram, araştırma ve uygulamalar [Positive psychology Theory, study and practices] (T. Doğan, Trans.). Ankara, Turkey: Nobel Yayın Dağıtım; 2014.

17. Compton WC, Hoffman E. Positive psychology: The science of happiness and flourishing. Belmont. 2012; CA: Wadsworth.

18. Kenyon M, Mayer DK, Owens, AK. Late and longterm effects of breast cancer treatment and surveillance management for the general practitioner. J Obst Gynecol Neonat Nurs. 2014; 43(3):382-98. [DOI:10.1111/1552-6909.12300] [PMID]

19. Leustek J, Theiss J. Family communication patterns that predict perceptions of upheaval and psychological well-being for emerging adult children following latelife divorce. J Family Stud. 2017; 52(23):1-20. [DOI:10.1080/13229400.2017.1352531]

20. Sarenmalm EKh, Mårtensson L, Andersson B, Karlsson P, Bergh I. Mindfulness and its efficacy for psychological and biological responses in women with breast cancer. Cancer Med. 2017; (2):1108-22. [DOI:10.1002/cam4.1052] [PMID] [PMCID]

21. Kollberg S, Wilderang $\mathrm{U}$, Thorsteinsdottir $\mathrm{T}$, Hugosson J, Wiklund P, Bjartell A, et al. Psychological Well-being and Private and Professional Psychosocial Support after Prostate Cancer Surgery: A Follow-up at 3, 12, and 24 Months after Surgery. Eur Urol Focus. 2015; (15):1-8. [DOI:10.1016/j.euf.2015.10.005] [PMID]

22. Vinayak S, Judge J. Resilience and Empathy as Predictors of Psychological Wellbeing among Adolescents. Int J Health Sci Res. 2018; 8(4):192-200.

23. Hu T, Xiao J, Peng J, Kuang X, He B. Relationship between resilience, social support as well as anxiety/depression of lung cancer patients: A cross-sectional observation study. J Can Res Ther.
2018; (14):72-7. [DOI:10.4103/jcrt.JCRT_849_17] [PMID]

24. Chow M, Tang W, Chan W, Sit W, Choi K. Resilience and well-being of university nursing students in Hong Kong: a cross-sectional study. BMC Medical Education. 2018; (18):2-8. [DOI:10.1186/s12909018-1119-0] [PMID] [PMCID]

25. Sagone E, De Caroli ME. Relationships between psychological well-being and resilience in middle and late adolescents. Procedia-Soc Behav Sci. 2014; (141):881-7. [DOI:10.1016/j.sbspro.2014.05.154]

26. Sisk D. Mindfulness and Its Role in Psychological Well-Being. Psych Res. 2017; 7(10):530- 5. [DOI:10.17265/2159-5542/2017.10.002]

27. Klainin-Yobas P, Ramirez D, Fernandez Z, Sarmiento J, Thanoi W. Examining the predicting effect of mindfulness on psychological well-being among undergraduate students: A structural equation modelling approach. Person Ind Differ. 2016; (91):638. [DOI:10.1016/j.paid.2015.11.034]

28. Bränström B, Kvillemo P, Brandberg Y, Moskowitz J. Self-report Mindfulness as a Mediator of Psychological Well-being in a Stress Reduction Intervention for Cancer Patients-A Randomized Study. Ann Behav Med. 2010; (39):151-61. [DOI:10.1007/s12160-010-9168-6] [PMID]

29. Grace A, Itunuoluwa A, Moyinoluwa O. Social Support and Personality Traits as Predictors of Psychological Wellbeing of Postpartum Nursing Mothers in Oyo State, Nigeria. Int J Car Sci. 2018; 11(2):704-18.

30. Katagami E, Tsuchiya H. Effects of Social Support on Athletes' Psychological Well-Being: The Correlations among Received Support, Perceived Support, and Personality. Psych. 2016; (7):1741-52. [DOI:10.4236/psych.2016.713163]

31. Rani K. Perceived Social Support and Psychological Well-Being: Testing the Unique Association and Gender Differences among Young Working Adults. Int J India Psych. 2016; 3(2):98-113. [DOI:10.25215/0302.065]

32. Olukolade O, Alao T, Adebisi A. The Role of social support and need for achievement on psychological well-being of below the knee amputees. IOSR J Hum Soc Sci. 2013; 18(1):23-7. [DOI:10.9790/0837$\underline{1812327]}$

33. Batool S, Ahmad A. Impact of Perceived Social Support on Psychological Well-being of Teenagers. Sci J Psych. 2013; 1-6. [DOI:10.7237/sjpsych/267]

34. Ahmadi S, Hosseini SM, Samani S. The Relationship between Family Communication Patterns and Adolescent Psychological Well-Being with Mediation of Identity Dimensions. Paper presented at The Second National Conference on Family Psychology. Tehran, Iran; 2014.

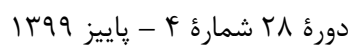

$$
\text { مجله مراقبت يرستارى و مامايى ابنسينا }
$$


35. Akhbarati F, Bashardost S. Predicting psychological well-being based on family functioning and students' basic psychological needs. Special Proceedings of the Third International Conference on Psychology and Educational Sciences. 2017; 374-9.

36. Ullah F. Personality Factors as Determinants of Psychological Well-Being among University Students. Int J India Psych. 2017; 4(2):5-16.

37. Khanjani M, Shahidi Sh, Fathabadi J, Mazaheri MA, Shokri, O. Factor structure and psychometric properties of the Ryff's scale of Psychological wellbeing, short form (18-item) among male and female students. Thought Behav Clin Psych. 2014; 8(32):2736.

38. Alipoor Z. The Effectiveness of Acceptance and Commitment-Based Education on Resiliency for Migraineurs. Thesis in Master of Science, Islamic Azad University, Hamadan Branch; 2015.

39. Anisi J, Majdian M, Joushan Lu M, Gohari Kamel Z. Validity and Reliability of the NEO Five-Factor Short Form Questionnaire in Students. J Behav Sci. 2011; 4(18):351 5.

40. Buchheld N, Grossman P, Walach H. Measuring mindfulness in insight meditation (Vipassana) and meditation- based psychotherapy: The development of the Freiburg Mindfulness Inventory (FMI). J Medit Medit Res. 2002; 1, 11-34.

41. Brown KW, Ryan RM. The benefits of being present: mindfulness and its role in psychological well-being. J Person Soc Psych. 2003; 84, 822-48. [DOI:10.1037/0022-3514.84.4.822] [PMID]

42. Feldman G, Hayes A, Kumar S, Greeson J, Laurenceau J. Mindfulness and emotion regulation: The development and initial validation of the cognitive and affective mindfulness scalerevised (CAMS-R). J Psych Behav Assess. 2007; 29(3):17790. [DOI:10.1007/s10862-006-9035-8]

43. Chadwick P, Hember M, Symes J, Peters E, Kuipers E, Dagnan, D. Responding mindfully to unpleasant thoughts and images: reliability and validity of the Southampton mindfulness questionnaire (SMQ). Brit J Clin Psych. 2008; 47(4):451-5. [DOI:10.1348/014466508X314891] [PMID]

44. Edwards DJA. Developing Evidence-Based Practice: The Role of Case-Based Research. Profession Psych: Res Practice. 2004; 35(6):589-97. [DOI:10.1037/0735-7028.35.6.589]

45. Salimi A, Jokar B, Nikpour R. Internet Communication in Life: Investigating the Role of Perceived Social Support and Loneliness in Internet Use. Psych Stud. 2009; 5(3):102-81.

46. Koshtaran T. The Relationship between Family Communication Patterns and Resilience in Shiraz University Students. Knowl Res Appl Psych. 2017; (39):43-55.

47. Gamst G, Guarino AH. Applied Multivariate Research (Design and Interpretation). Translated by H. Pasha Sharifi, V. Farzad, S. Rezakhani, H.
Hassanabadi, B. Izanloo, M. Habibi editors. Tehran: Iran National Library; 2012.

48. Husted H. The Relationship Between Psychological Well-Being and Successfully Transitioning to University Undergraduate Honors Theses. London: King's University College at Western University Canada; 2017.

49. Cassidy O. The Effects of Mindfulness, Sociability, Self Control and Yoga on Mental Health. Submission of Thesis to Norma Smurfit Library, National College of Ireland; 2017.

50. Souri H, Hejazi E, Ejei M. The Relationship between Resilience and Psychological Well-Being: A Mediator of Optimism. Knowl Res Appl Psych. 2013; 15(1):5-15.

51. Goudarz M, Foroughan M, Makarem A, Rashedi V. Relationship between Social Support and Subjective Well-Being in Older Adults. Salmand: Iran J Age. 2015; 10(3):110-9.

52. Abutalebi F, Khamsan A, Rastegomqadam M. The Relationship between Perceived Social Support with Mental Well-being and Academic Achievement of Preschool Girls. J Edu Psych. 2017; 14(48):147-68.

53. Shaheen M, Schindler L, Saar-Ashkenazy R, Bani Odeh K, Soreq H, Friedman A, et al. Victims of warPsychoendocrine evidence for the impact of traumatic stress on psychological well-being of adolescents growing up during the Israeli-Palestinian conflict. $\begin{array}{lll}\text { Psychophys. } & \text { 2020; } & \text { 57(1):e13271. }\end{array}$ [DOI:10.1111/psyp.13271] [PMID]

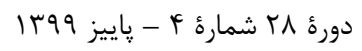

